\title{
Latent Heating and Cooling Rates in Developing and Nondeveloping Tropical Disturbances during TCS-08: Radar-Equivalent Retrievals from Mesoscale Numerical Models and ELDORA*
}

\author{
Myung-Sook Park, Andrew B. Penny, And Russell L. Elsberry \\ Department of Meteorology, Graduate School of Engineering and Applied Sciences, Naval Postgraduate School, \\ Monterey, California \\ BRIAN J. BILLINGS \\ National Research Council, Monterey, California
}

JAMES D. DOYLE

Naval Research Laboratory, Monterey, California

(Manuscript received 21 November 2011, in final form 20 July 2012)

\begin{abstract}
Latent heating and cooling rates have a critical role in predicting tropical cyclone formation and intensification. In a prior study, Park and Elsberry estimated the latent heating and cooling rates from aircraft Doppler radar [Electra Doppler Radar (ELDORA)] observations for two developing and two nondeveloping tropical disturbances during the Tropical Cyclone Structure 2008 (TCS-08) field experiment. In this study, equivalent retrievals of heating rates from two mesoscale models with 1-km resolution are calculated with the same radar thermodynamic retrieval. Contoured frequency altitude diagrams and vertical profiles of the net latent heating rates from the model are compared with the ELDORA-retrieved rates in similar cloud-cluster regions relative to the center of circulation.

In both the developing and nondeveloping cases, the radar-equivalent retrievals from the two models tend to overestimate heating for less frequently occurring, intense convective cells that contribute to positive vorticity generation and spinup in the lower troposphere. The model maximum cooling rates are consistently smaller in magnitude than the heating maxima for the nondeveloping cases as well as the developing cases. Whereas in the model the cooling rates are predominantly associated with melting processes, the effects of evaporative cooling are underestimated in convective downdraft regions and at upper levels. Because of the net warming of the columns, the models tend to overintensify the lower-tropospheric circulations if these intense convective cells are close to the circulation center. Improvements in the model physical process representations are required to realistically represent the evaporative cooling effects.
\end{abstract}

\section{Introduction}

Studies of tropical cyclone formation in the western North Pacific have focused on such synoptic

\footnotetext{
* Supplemental information related to this paper is available at the Journals Online website: http://dx.doi.org/10.1175/JAS-D-110311.s1.

Corresponding author address: Dr. Myung-Sook Park, Department of Meteorology, Naval Postgraduate School, 589 Dyer Road, Monterey, CA 93943.

E-mail:mpark@nps.edu
}

disturbances as the monsoon depression (Harr et al. 1996), monsoon trough (Lander 1994), easterly wave (Frank 1970; Ritchie and Holland 1999), or tropical upper-tropospheric trough cells (Sadler 1976). In the tropical cyclone formation component of the Tropical Cyclone Structure 2008 (TCS-08; Elsberry and Harr 2008) field experiment during August-September 2008 , the primary focus was on the contribution of mesoscale convective systems (MCSs) and the associated mesoscale convective vortices that are embedded in the synoptic circulation; that is, dynamic and thermodynamic structures of MCSs and small-scale physical processes were hypothesized to determine the location and 
TABLE 1. Four of six TCS-08 cases examined in Park and Elsberry (2013) at different tropical cyclone development stages and the ELDORA observation times for which the latent heating and cooling rates were calculated.

\begin{tabular}{llc}
\hline \hline Development stage & \multicolumn{1}{c}{ TCS-08 case } & ELDORA observation times used \\
\hline Developing stage & 1) Pre-reintensification Sinlaku & $0140-0200$ UTC 17 Sep \\
& 2) Pre-Nuri & 0315-0345 UTC 16 Aug \\
Nondeveloping stage & 3) TCS25 & 0300-0330 UTC 29 Aug \\
& 4) TCS51 & 0200-0230 UTC 4 Oct \\
\hline
\end{tabular}

timing of tropical cyclone formation. Increased computing capability has enabled numerical simulations of the TCS-08 cases to be performed at deep convectionpermitting resolution.

The objective of this study is to examine comparable latent heating rate retrievals in two mesoscale numerical models with the retrievals from the Doppler radar observations of convection in two developing cases and two nondeveloping circulations examined in Park and Elsberry (2013). The motivation for evaluating these mesoscale models stems from a number of recent numerical simulations of tropical cyclone formation. Hendricks et al. (2004) used a high-resolution $(3 \mathrm{~km})$ mesoscale model to simulate the formation of Hurricane Diana and found a close relationship between convective updrafts and vertical vorticity anomalies. They suggested that mesoscale vortices and the associated heating contributed to the development of the primary circulation via the interaction and merger of the positive vorticity anomalies. In a highly idealized numerical simulation from a preexisting axisymmetric vortex, Montgomery et al. (2006) also emphasized the connection between strong convective updrafts and positive vorticity anomalies [so-called vortical hot towers (VHTs)] and their mergers. In particular, they suggested that a primary forcing for the synoptic-scale vortex intensification was the latent heat release in the VHTs. In several idealized simulations from a preexisting mesoscale convective vortex, Nolan (2007) found sporadic convection occurred for 48-72 h before a low-level vortex formed and rapidly intensified. Prior to the development of the low-level vortex, a midlevel vortex developed as the inner core was humidified mainly due to precipitation from deep convective towers. In high-resolution numerical simulations of Tropical Storm Gert (2005) by Braun et al. (2010), stratiform precipitation regions contributed to a significant increase in cyclonic circulation at midlevels; however, vortex enhancement at low levels that was necessary for tropical cyclone formation was associated with mergers of convective cells.

These prior studies suggest different contributions from the convective or stratiform regions of the MCS in increasing the cyclonic vorticity near the surface or in midlevels, and thereby which pathway (axisymmetrization, vortex merging, or other interactions) the intensification to a tropical cyclone vortex occurs. All of these studies emphasized the importance of the simulated latent heating rate as a crucial physical process leading to a tropical cyclone circulation.

Despite these significant impacts, numerically simulated latent heating and cooling rates have rarely been compared with retrievals of latent heating rate from observations. Convection in numerical models depends on the physical representations of the planetary boundary layer, cloud microphysics, and subgrid cumulus parameterization. A convection-permitting horizontal grid interval of $1-3 \mathrm{~km}$ avoids the use of a convective parameterization scheme, which is a potential error source for latent heating and cooling rates in coarse-resolution simulations. However, predicting tropical cyclone formation is still challenging even when using such highresolution simulations, since parameterizations of the boundary layer and cloud microphysics also introduce uncertainties in the latent heating and cooling rates (Nolan et al. 2009; Fovell et al. 2009). Park and Elsberry (2013) applied the thermodynamic retrieval algorithm of Roux et al. (1993) to calculate latent heating and cooling rates at different tropical cyclone stages from the Naval Research Laboratory P-3 Electra Doppler Radar (ELDORA) observations during the TCS-08 experiment. Six TCS-08 ELDORA missions were examined (Table 1): two tropical disturbances prior to tropical depression (TD) formation and reintensification of typhoon (pre-Nuri and pre-reintensification of Sinlaku); two tropical disturbances (TCS25 and TCS51) that failed to develop; and two mature tropical cyclone rainband cases (Typhoons Jangmi and Sinlaku). While Park and Elsberry (2013) describe the potential error sources in the latent heating and cooling rates from the Doppler radar observations, they were effectively considered to be "ground truth" relative to the latent heating rate retrievals from non-Doppler precipitation radar (PR) observations on the Tropical Rainfall Measuring Mission (TRMM) satellite. While the heating rates from the ELDORA and the TRMM generally agreed within the uncertainty of the ELDORA observations [appendix B of Park and Elsberry (2013)], the TRMM cooling rates were significantly smaller than the ELDORA cooling rates in all six cases.

In this study, the Advanced Research Weather Research and Forecasting model (WRF; Skamarock et al. 
2008) and the Coupled Ocean-Atmosphere Mesoscale Prediction System-Tropical Cyclones (COAMPS-TC; Hodur 1997; Chen et al. 2003) are used with 1-km horizontal resolution. The primary objective is to compare the model-derived and ELDORA-retrieved latent heating rates in common cloud clusters in the two developing and two nondeveloping tropical disturbances (Table 1). Rather than attempt to match individual convective cells in the ELDORA observations and numerical simulations, the contoured frequency altitude diagrams (CFADs) as used in Park and Elsberry (2013) are compared over areas encompassing cloud clusters with similar structure and positions relative to the center of circulation. Park and Elsberry (2013) demonstrated that the ELDORA maximum heating rates are larger than the maximum cooling rates in the developing tropical cyclone cases, and a shift of the heating maximum from the middle to the lower troposphere was more favorable for inducing low-level convergence and spinup of a cyclone. Since significant low-level evaporative cooling in the convectivescale downdrafts and stratiform regions are crucial components of MCSs (Houze 2004), the profiles of cooling rates from the numerical simulation retrievals will be another important focus.

Data and methodology will be described in section 2 . It will be demonstrated that the model-simulated latent heating rates cannot be directly compared with the ELDORA-retrieved heating rates, so the Doppler radar thermodynamic retrieval will be applied to the model simulations to calculate comparable heating rates. Direct comparisons of radar-equivalent latent heating rates from the numerical simulations with the ELDORAderived latent heating rates will be shown for the prereintensification of Typhoon Sinlaku and pre-Nuri, and for the two nondeveloping (TCS25 and TCS51) circulations in sections 3 and 4, respectively. In each case study, the predicted evolution of the system circulation will be also investigated to understand the possible impact of the latent heating and cooling rates. A summary and a discussion are given in section 5 .

\section{Data and methodology}

\section{a. Numerical model setup}

Four numerical simulations with WRF have been performed for the two developing and two nondeveloping cases with a horizontal grid size of $1 \mathrm{~km}$ (Table 2), which is the same grid size as the ELDORA data. One simulation with COAMPS-TC for case 3 TCS25 has been conducted with the same resolution. The high-resolution, 3D wind and radar reflectivities from these five simulations were used to calculate the radar-equivalent latent heating rates with a method to be described in section $2 \mathrm{c}$. COAMPS-TC simulations for the other cases (Table 2) that were integrated with a $3-\mathrm{km}$ grid size for comparison with WRF simulations will not be discussed in detail.

For the five simulations, domains 1,2,3, and 4 had horizontal grid sizes of 27, 9,3, and $1 \mathrm{~km}$, respectively. Except for the two nondeveloping cases, both inner grids in WRF moved with the system. The innermost grid in COAMPS-TC also moved with the system. WRF has 33 vertical levels, and COAMPS-TC has 31 vertical levels. Because the ELDORA retrievals have a 500-m vertical resolution from near surface to $15 \mathrm{~km}$, the modelderived fields were vertically interpolated to a $500-\mathrm{m}$ grid.

Initial and lateral boundary conditions for WRF simulations were extracted from 6-hourly European Centre for Medium-Range Weather Forecasts (ECMWF) operational analyses with $0.25^{\circ}$ horizontal resolution and for COAMPS-TC simulations were obtained from 3-hourly Navy Operational Global Atmospheric Prediction System forecasts with $0.5^{\circ}$ horizontal resolution. Initial times for each case (Table 2) were selected between 24 and $48 \mathrm{~h}$ prior to the ELDORA observations to minimize model spinup issues and to ensure that the numerical simulation is a reasonably accurate prediction of the circulation and convective clusters. An exception is the WRF pre-Nuri simulation that was initiated only $15 \mathrm{~h}$ before the ELDORA observations to obtain a more representative low-level circulation that existed during the ELDORA observations.

Physical process representations selected for WRF simulations include the Yonsei University boundary layer scheme (Hong et al. 2006), the fifth-generation Pennsylvania State University-National Center for Atmospheric Research (NCAR) Mesoscale Model (MM5) similarity theory surface-layer scheme (Skamarock et al. 2008), the five-layer thermal diffusion land surface scheme (Dudhia 1996), and the Kain-Fritsch cumulus scheme (Fritsch and Kain 1993; Kain 2004) on the 27- and 9-km grids. Radiative processes were calculated using the Rapid Radiative Transfer Model (RRTM; Mlawer et al. 1997) for longwave radiation and Dudhia (1989) for shortwave radiation. Bulk parameterization of cloud microphysics was the WRF Single-Moment 6-class cloud microphysics scheme (Hong et al. 2004), which includes water vapor, cloud water, cloud ice, rain, snow, and graupel.

The COAMPS-TC physics packages were a 1.5 -order turbulence closure planetary boundary layer parameterization scheme, the Wang et al. (2002) surface-layer parameterization, the Kain-Fritsch (Fritsch and Kain 1993; Kain 2004) cumulus scheme, and radiative transfer parameterizations for shortwave and longwave radiation following Harshvardhan et al. (1987). Bulk parameterization of cloud microphysics was based on a modified 
TABLE 2. Summary of four WRF simulations (runs 1-4) and a COAMPS-TC simulation (run 5) on domain 4 used as the input to the radar-equivalent latent heating rates and two COAMPS-TC simulations (runs 6 and 7) with only three domains for comparison with the WRF simulations. Each simulation is characterized by 1) storm and model and 2) model integration times, domain size, resolution, and type (fixed or moving).

\begin{tabular}{|c|c|c|}
\hline \multirow[b]{2}{*}{ Run No. } & \multirow[b]{2}{*}{ Storm and model } & Integration time \\
\hline & & $\begin{array}{l}\text { Domain No.: No. of grid points, horizontal resolution of grids } \\
\text { (indicated if moving) }\end{array}$ \\
\hline \multirow[t]{5}{*}{1} & Pre-reintensification TY Sinlaku WRF & Time: 0000 UTC 16 Sep-0000 UTC 18 Sep \\
\hline & & $1: 328 \times 167,27 \mathrm{~km}$ \\
\hline & & $2: 250 \times 250,9 \mathrm{~km}$ (moving) \\
\hline & & 3: $400 \times 400,3 \mathrm{~km}$ (moving) \\
\hline & & 4: $979 \times 979,1 \mathrm{~km}$ (moving) \\
\hline \multirow[t]{5}{*}{2} & Pre-Nuri WRF & Time: 1200 UTC 15 Aug-0000 UTC 17 Aug \\
\hline & & $1: 275 \times 177,27 \mathrm{~km}$ \\
\hline & & 2: $301 \times 301,9$ km (moving) \\
\hline & & 3: $649 \times 649,3 \mathrm{~km}$ (moving) \\
\hline & & 4: $979 \times 979,1 \mathrm{~km}$ (moving) \\
\hline \multirow[t]{5}{*}{3} & TCS25 WRF & Time: 1200 UTC 27 Aug-1200 UTC 30 Aug \\
\hline & & $1: 188 \times 147,27 \mathrm{~km}$ \\
\hline & & 2: $493 \times 337,9 \mathrm{~km}$ \\
\hline & & 3: $718 \times 634,3 \mathrm{~km}$ \\
\hline & & 4: $973 \times 973,1 \mathrm{~km}$ \\
\hline \multirow[t]{5}{*}{4} & TCS51 WRF & Time: 1200 UTC 2 Oct-0000 UTC 5 Oct \\
\hline & & 1: $194 \times 156,27 \mathrm{~km}$ \\
\hline & & $2: 388 \times 319,9 \mathrm{~km}$ \\
\hline & & 3: $709 \times 709,3 \mathrm{~km}$ \\
\hline & & 4: $979 \times 979,1 \mathrm{~km}$ \\
\hline \multirow[t]{5}{*}{5} & TCS25 COAMPS-TC & Time: 1200 UTC 27 Aug-1200 UTC 30 Aug \\
\hline & & $1: 188 \times 147,27 \mathrm{~km}$ \\
\hline & & $2: 493 \times 337,9 \mathrm{~km}$ \\
\hline & & $3: 718 \times 634,3 \mathrm{~km}$ \\
\hline & & 4: $973 \times 973,1 \mathrm{~km}$ \\
\hline \multirow[t]{5}{*}{6} & Reintensification Typhoon Sinlaku COAMPS-TC & Time: 0000 UTC 16 Sep (initialized by the previous $12-\mathrm{h}$ \\
\hline & & forecasts)-0000 UTC 18 Sep \\
\hline & & $1: 301 \times 253,27 \mathrm{~km}$ \\
\hline & & $2: 202 \times 202,9 \mathrm{~km}$ (moving) \\
\hline & & 3: $202 \times 202,3 \mathrm{~km}$ (moving) \\
\hline \multirow[t]{4}{*}{7} & TCS51 COAMPS-TC & Time: 0000 UTC 3 Oct-1800 UTC 4 Oct \\
\hline & & $1: 301 \times 253,27 \mathrm{~km}$ \\
\hline & & $2: 304 \times 304,9 \mathrm{~km}$ \\
\hline & & $3: 490 \times 451,3 \mathrm{~km}$ \\
\hline
\end{tabular}

version of Rutledge and Hobbs (1984) with prognostic equations for mixing ratios of cloud droplets, cloud ice, rain, snow, and graupel. A Tiedtke et al. (1988) approach is used to represent the vertical mixing processes associated with shallow convection.

\section{b. Equivalent model latent heating rates from the radar thermodynamic retrieval method}

A flowchart to indicate the processing of the modelsimulated fields to obtain the latent heating and cooling rates that are equivalent to the ELDORA thermodynamic retrieval is given in Fig. 1. Note that the thermodynamic retrieval method estimates latent heating rates from advection of the retrieved virtual cloud temperature, which neglects radiation, molecular diffusion, and especially the time tendencies of the motion and hydrometeors [appendix A of Park and Elsberry (2013)]. Park and Elsberry (2013) indicate that these ELDORA retrievals are not representative of the instantaneous rates that might be inferred from a single sweep of the radar. Rather, they propose the ELDORA retrievals represent an average over the time lag among Doppler measurements from the forward- and backward-pointed antennas that may be up to 5-10 min (Hildebrand et al. 1996). The variational minimization with a mass continuity constraint that is applied in the radar retrieval effectively averages over some localized three-dimensional area swept out by the forward and backward views. In addition, a three-step Leise (1982) filter is applied to smooth the velocity fields in space, but it will also reduce 


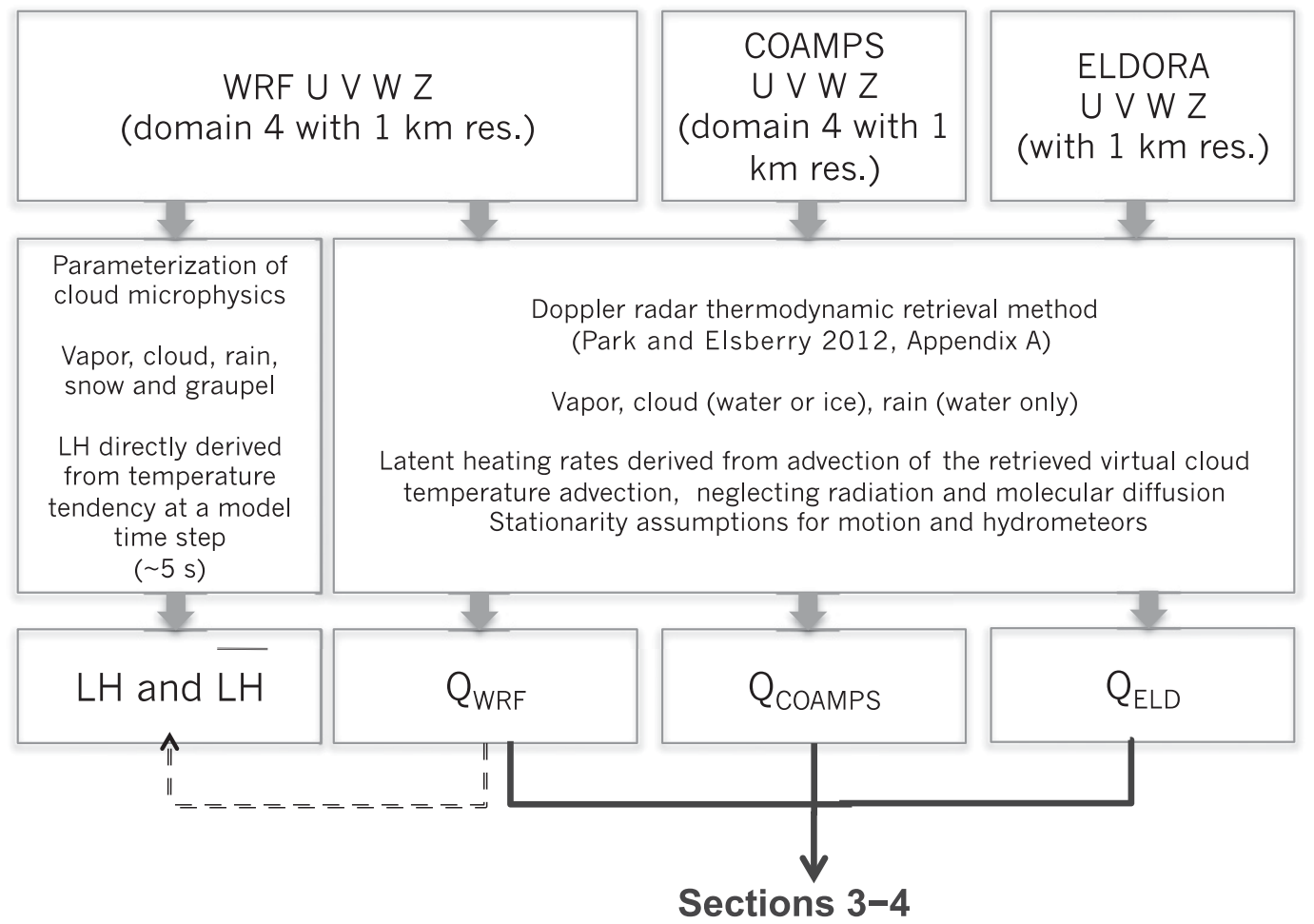

FIG. 1. Flowchart to illustrate the effects of the stationarity and moist physics assumptions in the ELDORA thermodynamic retrieval system (large box in middle row) compared with the instantaneous heating and cooling rates and moist physics in the numerical models (smaller box in middle row). In the left column, the instantaneous model latent heating $(\mathrm{LH})$ and a time-averaged latent heating $(\overline{\mathrm{LH}})$ are used for the CFADs in Figs. 2a and $2 \mathrm{~b}$, which are compared with the $Q_{\mathrm{WRF}}$ (Fig. 2c) in which the WRF three-dimensional wind fields $(u, v$, and $w)$ and simulated radar reflectivity $Z$ are passed through the radar thermodynamic retrieval system. In sections 3 and 4 , the $Q_{\mathrm{WRF}}$ and $Q_{\mathrm{COAMPS}}$ derived from the thermodynamic retrieval system in this manner will be compared with the $Q_{\text {ELD }}$ retrievals from the 1-km ELDORA observations that were passed through the radar thermodynamic retrieval system (far right column).

the local maxima and minima associated with shorttime-scale convective updrafts and downdrafts. Note also that this approach differs from Guimond et al. (2011), who were able to include tendency terms from modelsimulated values without smoothing the highly variable, local variability on the convective scales.

By contrast, the latent heating and cooling rates in the models are calculated each time step $(\sim 5.5 \mathrm{~s}$ on domain 4 ) in response to vertical velocities that exactly satisfy the mass continuity equation in each $1-\mathrm{km}$ grid box. Thus, a variational minimization with mass continuity constraint is not necessary with the self-consistent, three-dimensional velocity field in the model. Furthermore, the model-retrieved latent heating rates $Q_{\mathrm{WRF}}$ do not include some of the uncertainties that the radarretrieved latent heating rates $Q_{\mathrm{ELD}}$ have due to radar attenuation, beam spreading, ground clutter removal, etc. [see Park and Elsberry (2013) for the procedures for radar wind analyses and uncertainty estimates]. Indeed, it would be difficult to estimate the contribution of these effects to the uncertainties in the ELDORA retrievals, especially as they likely depend on the distance from the aircraft.

Park and Elsberry (2013) followed Nolan (2007) and Rogers (2010) in using CFADs to characterize the threedimensional structures and magnitudes of latent heating and cooling rates from the models. In these CFADs, frequencies are normalized by the total nonmissing grid numbers of all levels. Park and Elsberry (2013, their Fig. 4) suggest the heating and cooling rates from the normalized frequency contours less than $10^{-3}\left(10^{-4}\right.$, $10^{-5}$, and $10^{-6}$ ) represent the mesoscale contribution associated with convective cells and the normalized frequency contours of $10^{-3}$ and larger frequencies may be attributed to the background, more frequently occurring convection.

Using these CFADs, the potential contributions from the very-short-time-scale latent heating and cooling rates in WRF for case 3TCS25 are illustrated (Fig. 2a; labeled LH) by averaging the instantaneous values over $30 \mathrm{~min}$ 
a) $\mathrm{LH}$

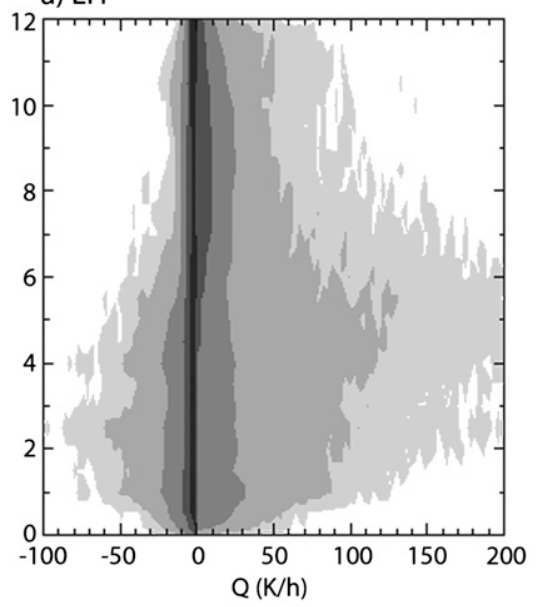

b) $\overline{\mathrm{LH}}$

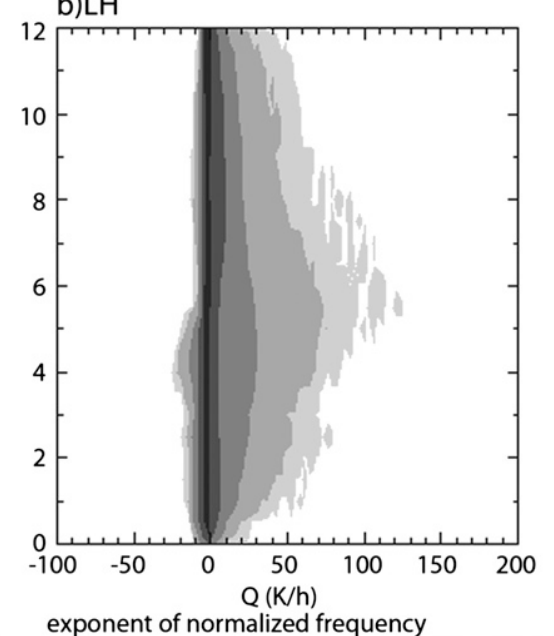

c) QWRF

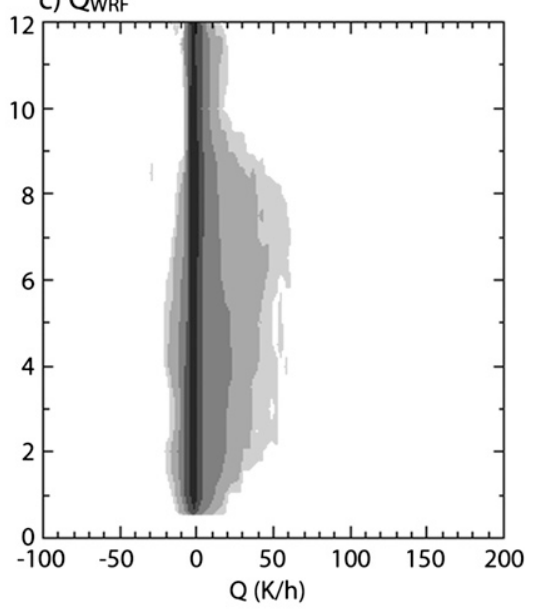

$-1$

FIG. 2. CFADs for three latent heating rates (defined in Fig. 1): (a) instantaneous model heating rate, (b) LH averaged for $30 \mathrm{~min}$, and (c) the equivalent model heating rate retrieved by passing the model-predicted $u, v, w$, and $Z$ fields through Doppler radar thermodynamic retrieval system based on WRF simulation for case 3 TCS25 with 1-km grid spacing. Note the radar thermodynamic retrieval system assumes stationarity, excludes snow and graupel phases, and includes a three-step Leise space filter.

(Fig. 2b). The rationale for the 30 -min average is that this might be considered as the time scale of some of the strong convective updrafts that were contributing to the latent heating rates greater than $200 \mathrm{~K} \mathrm{~h}^{-1}$ in the model. Indeed, simply time averaging at grid points over the convective life cycle reduces the maximum heating rates of about 120 and $200 \mathrm{~K} \mathrm{~h}^{-1}$ that are associated with the least frequently occurring (CFADnormalized frequencies of $10^{-5}$ and $10^{-6}$ ) convective elements to about 75 and $120 \mathrm{~K} \mathrm{~h}^{-1}$, respectively (Fig. 2b). The maximum heating rates for the $10^{-4}$ frequency cells are less affected by the time averaging, which likely indicates that a large number of smaller cells are in various stages of their life cycle within the $2^{\circ} \times 2^{\circ}$ area. Similarly, the maxima of instantaneous cooling rates in the model (Fig. 2a) associated with the less frequently occurring cells are reduced by time averaging (Fig. 2b).

The purpose of this time averaging is simply to illustrate that neither the instantaneous nor a simple time average of the model-simulated LH can be directly compared with the ELDORA retrievals. In addition to not resolving the rapid time variations, the radar thermodynamic retrieval system is not represented by simple averaging of the time variability over $30 \mathrm{~min}$. Note also that the radar retrieval does not consider the snow and graupel phases that are included in the model microphysics, so that the model has more heating above the freezing level than is being represented by the retrieval system.
Given this demonstration of the rapid time variations in the model instantaneous heating and cooling rates, the strategy (suggested by P. Reasor 2011, personal communication) was to pass WRF-predicted 3D wind components and simulated radar reflectivity through the radar thermodynamic retrieval system to derive equivalent model heating rates for comparison with the ELDORA observations (indicated on the far right side of Fig. 1).

WRF (COAMPS-TC) radar-equivalent latent heating rates, labeled as $Q_{\mathrm{WRF}}\left(Q_{\mathrm{COAMPS}}\right)$ in Fig. 1 , do indeed correspond more closely to the $Q_{\text {ELD }}$ of Fig. 1 . Some larger maximum heating values (especially in the upper troposphere) for these same frequencies may be attributed to the inclusion (exclusion) of the snow and graupel phases in the model (thermodynamic retrieval system). Given the similar large reductions in both the maximum heating and cooling rates in Figs. 2b and 2c, the $Q_{\mathrm{WRF}}$ and $Q_{\text {COAMPS }}$ are considered to be valid for comparison with the retrievals of latent heating and evaporative cooling derived from $Q_{\mathrm{ELD}}$ in Park and Elsberry (2013). Such comparison must always consider the uncertainties in the ELDORA observations (e.g., attenuation, ground clutter, and use of an environmental sounding), and the additional heating aloft associated with the snow and graupel phases in the model. However, the radar-equivalent model retrievals with the variational minimization and the application of the three-step Leise filter do treat the vertical velocities that are the primary determinant of the latent heating and cooling rates. The focus in the comparison 
a)

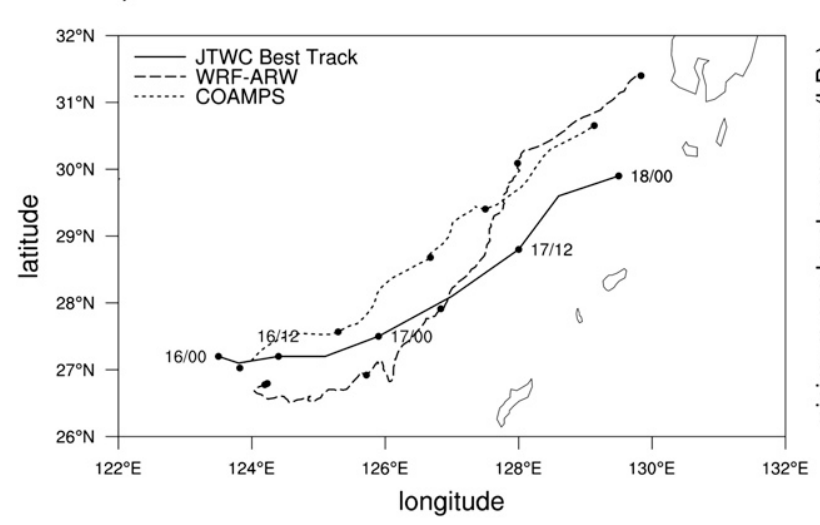

b)

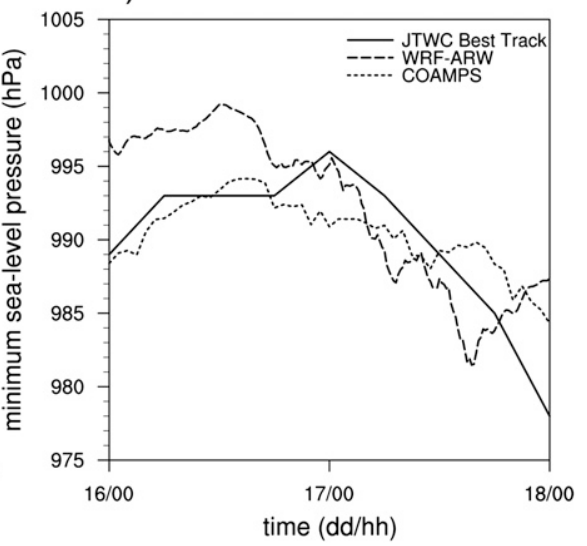

FIG. 3. (a) Track and (b) minimum SLP evolutions for case 1 reintensification of Typhoon Sinlaku for the WRF and COAMPS-TC simulations from 0000 UTC 16 Sep (16/00) to 0000 UTC 18 Sep (18/00) in comparison with the track and SLP from the JTWC.

between the ELDORA and model rates in the following sections will be on features considered to represent differences greater than the ELDORA uncertainties.

\section{Simulations of developing systems}

\section{a. Simulations of reintensifying Typhoon Sinlaku circulation (case 1)}

The first case study is a comparison of the numerical simulation of the reintensification of Typhoon Sinlaku with the ELDORA observations. Sanabia (2010) extensively studied the ELDORA observations of an intense MCS between 0130 and 0200 UTC 17 September 2008. Park and Elsberry (2013) also focused on this ELDORA mission. Both the WRF and the COAMPS-TC simulations were initialized at 0000 UTC 16 September, which is about $24 \mathrm{~h}$ before the ELDORA observations, and were integrated until 0000 UTC 18 September (Table 2). Both models predicted a northeastward track of the reintensifying typhoon during the integration (Fig. 3a). However, the simulated tracks are displaced north of the Joint Typhoon Warning Center (JTWC) position by 0000 UTC 17 September, which is the approximate time of the ELDORA observations. While the agreement with the JTWC sea level pressure (SLP) happens to be good (Fig. 3b) at the time of the ELDORA observations, this is because the initial WRF SLP was too high, and a 12-h period of filling was followed by a deepening period. WRF then predicted a 10-hPa deepening to $985 \mathrm{hPa}$ between 0100 and 0600 UTC 17 September (Fig. 3b). By contrast, the initial COAMPS-TC SLP and first 24-h slow filling were approximately correct, but then the deepening rate (reintensification) of Sinlaku was underpredicted.
At 0000 UTC 17 September, WRF has simulated a surface cyclonic circulation centered near $27.8^{\circ} \mathrm{N}, 128^{\circ} \mathrm{E}$ with a minimum SLP of $996 \mathrm{hPa}$. As in ELDORA observations (Fig. 4d), WRF-simulated convective bursts (Fig. 4a) were displaced to the east of the circulation center. Note that active convective bursts with maximum reflectivities greater than $45 \mathrm{dBZ}$ are simulated about $70 \mathrm{~km}$ east of this remnant Sinlaku circulation center. The convective burst observed by ELDORA was also about $0.8^{\circ}$ east of the circulation center (see Figs. $4 \mathrm{c}$ and $4 \mathrm{~d}$ ).

COAMPS-TC also simulated the remnant Sinlaku circulation with convective bursts at 0000 UTC 17 September (Fig. 4b), but it predicted the strongest convective bursts would be far east of the center of circulation. The possible contributions of these horizontal distributions of convection on the tropical cyclone predictions will be discussed in next subsection.

\section{b. Equivalent retrievals of model latent heating and cooling rates for case 1}

The CFADs for $Q_{\mathrm{WRF}}$ that are equivalent retrievals to $Q_{\text {ELD }}$ from Park and Elsberry (2013) are shown in Figs. 5a and 5b. Notice that WRF-retrieved heating maxima are about 18 and $45 \mathrm{~K} \mathrm{~h}^{-1}$ for normalized frequencies of $10^{-4}$ and $10^{-5}$, respectively (Fig. 5a), and the corresponding ELDORA heating rates are 25 and $45 \mathrm{~K} \mathrm{~h}^{-1}$, respectively (Fig. 5b). By contrast, WRF cooling rates underestimate ELDORA cooling maxima. Sanabia (2010) showed that westerly vertical wind shear in this tropical cyclone resulted in eastward tilting of the updrafts in the deep convection, such that large raindrops fell into low-level dry air, which then led to large evaporative-cooling magnitudes and convective-scale downdrafts in the lower atmosphere (Fig. 5b). Strong 
a) WRF ref. (4km) 9/17 0000 UTC

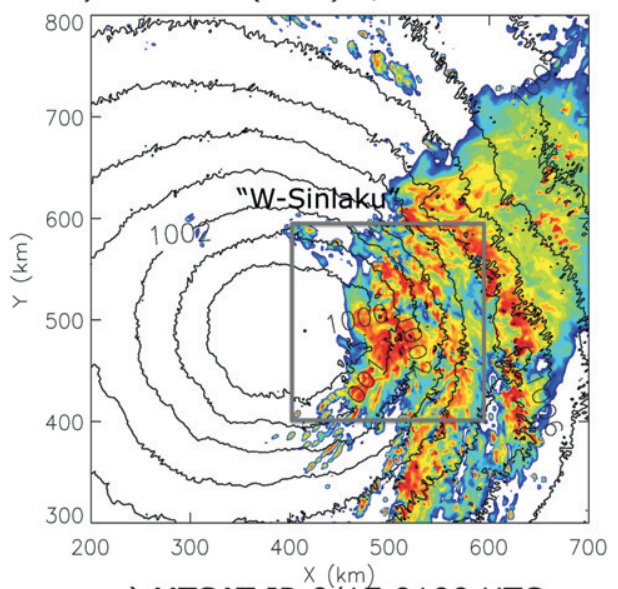

c) MTSAT IR $9 / 170100$ UTC

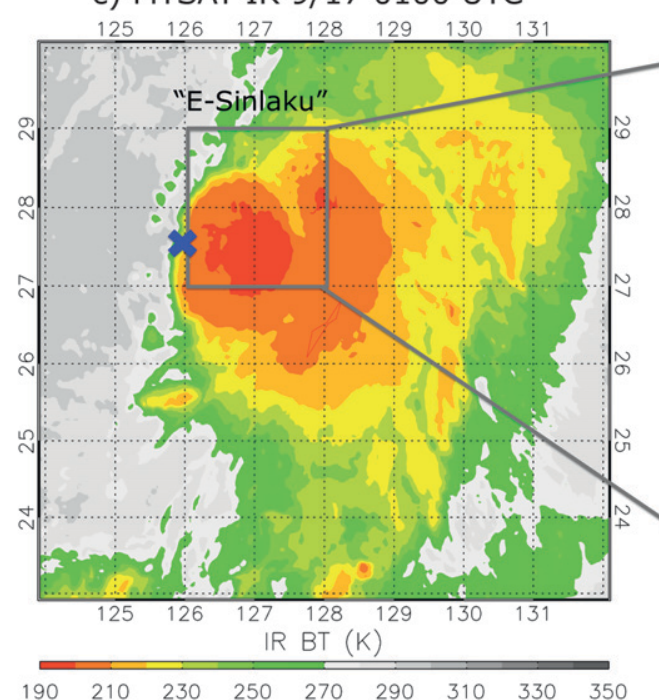

b) COAMPS-TC ref. (4km) 9/17 0000 UTC

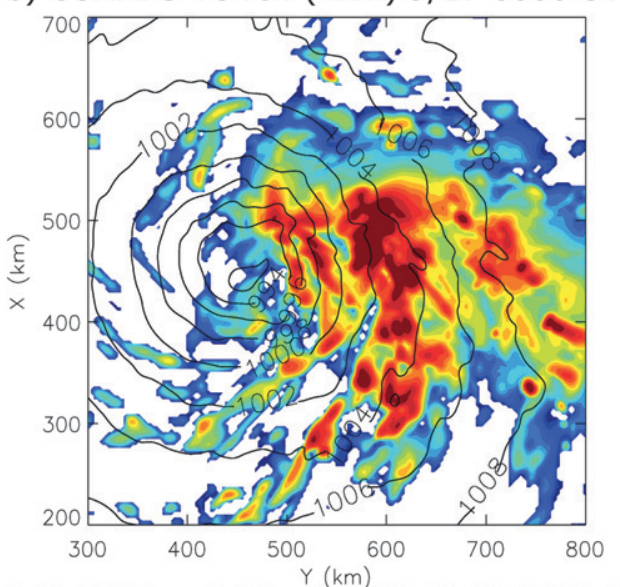

d) ELDORA ref. (4km) 9/19 0130-0200 UTC

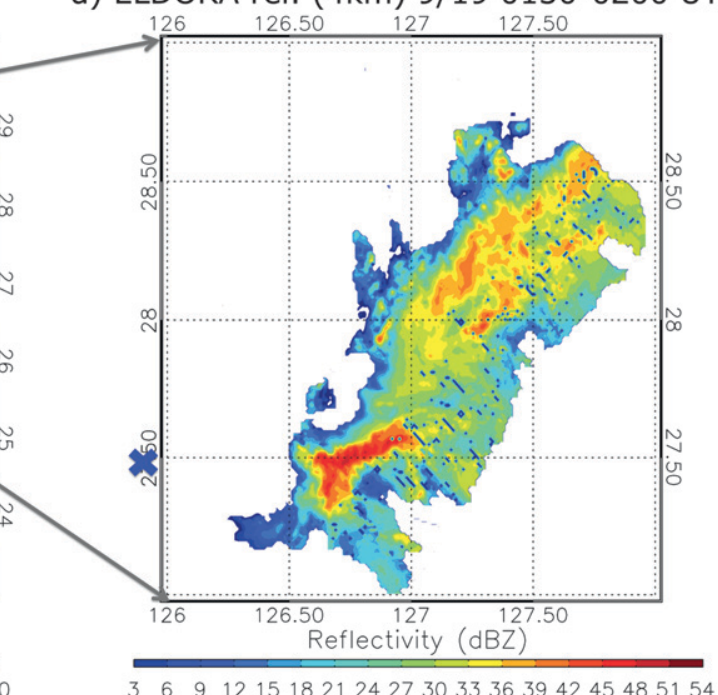

FIG. 4. Reflectivities (dBZ) with SLPs (contour, 1-hPa interval) at 0000 UTC 17 Sep 2008 from (a) WRF at 4-km elevation and (b) COAMPS-TC at surface, (c) infrared brightness temperature (K) at 0100 UTC, and (d) the ELDORA-observed reflectivities at $4 \mathrm{~km}$ between 0130 and 0200 UTC. The reflectivity scale is below (d) and the brightness temperature scale is below (c). The boxes in each panel indicate the regions over which the CFADs in Fig. 5 are calculated. The blue cross at $27.5^{\circ} \mathrm{N}, 125.9^{\circ} \mathrm{E}$ indicates the center of the system at $0000 \mathrm{UTC}$ according to the JTWC.

westerly environmental wind shears $\left(>8 \mathrm{~m} \mathrm{~s}^{-1}\right)$ were simulated in the deep troposphere near the circulation center and especially farther north (see Fig. S1 in the supplemental material). Accordingly, the simulated convective towers tend to be tilted eastward with the strongest updrafts with the largest latent heat release in the upper levels around $7 \mathrm{~km}$ (see Fig. S2 in the supplemental material).

Similarly, the radar-equivalent heating maximum from the WRF simulation is at upper levels for the least frequently occurring convective cells with frequency contours of $10^{-5}$ and $10^{-6}$ (Fig. 5a). In addition, the WRF simulation has a secondary heating maximum around
2-6 $\mathrm{km}$ for the $10^{-4}$ frequency. Thus, the WRF simulation has some ability in representing the upper-level latent heating maxima, although the magnitudes are a little underestimated. However, the evaporative cooling below the tilted convective towers and the associated low-level downdrafts are not properly represented in the model. Whereas the WRF cooling rate maximum is between 4 and $6 \mathrm{~km}$ (i.e., near the freezing level) for the least frequently occurring convective cells with frequency contours less than $10^{-3}$ (Fig. 5a), the $Q_{\mathrm{ELD}}$ cooling rate maximum is around $2-4 \mathrm{~km}$ (Fig. $5 \mathrm{~b}$ ).

These low-level cooling rates in WRF are not large enough to compensate for the corresponding heating 

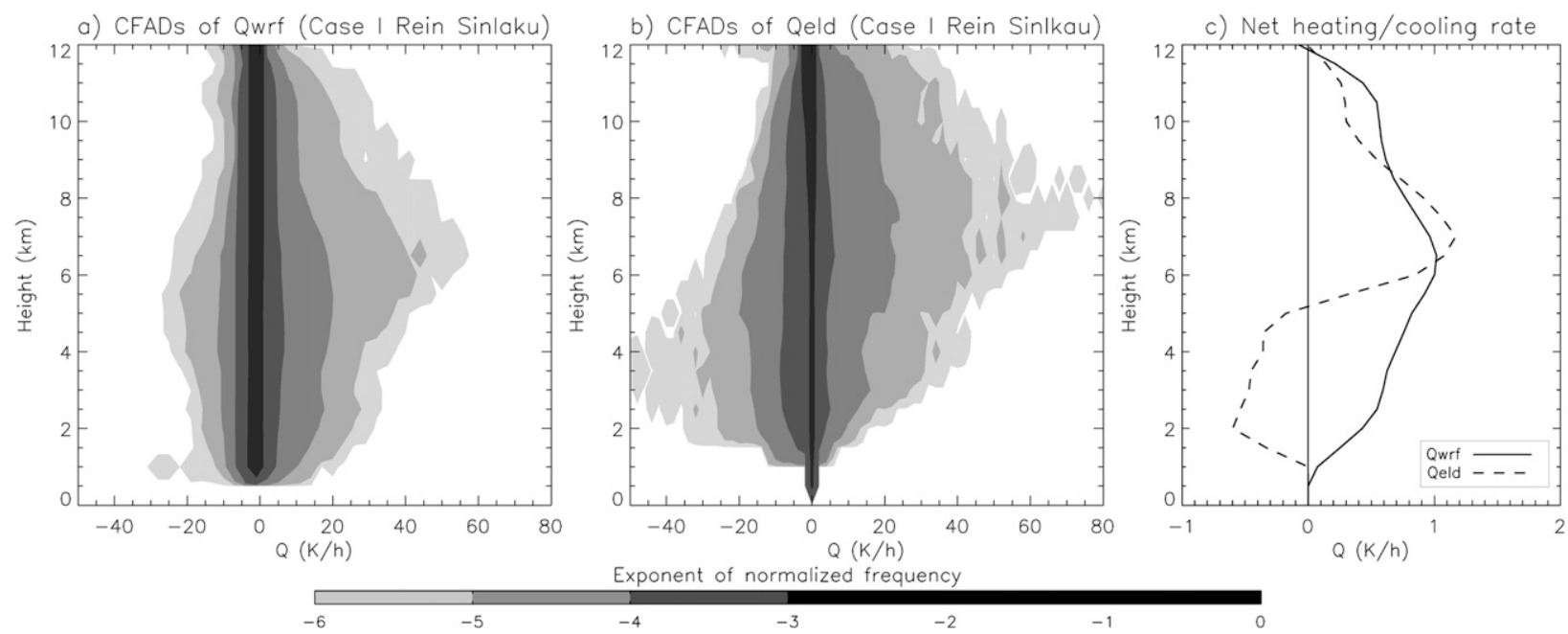

FIG. 5. The CFADs for case 1 reintensification of Typhoon Sinlaku for latent heating and cooling rates $\left(\mathrm{K} \mathrm{h}^{-1}\right)$ from equivalent retrievals for (a) WRF and (b) ELDORA. The shading (scale at bottom) indicates the normalized frequency contours ranging from $10^{\circ}$ to $10^{-6}$. (c) Profiles of net heating and cooling rates from WRF (solid) and ELDORA (dashed) averaged over the box domains in Fig. 4.

rates for the less frequently occurring cells, which are responsible for $85 \%$ of the net heating around $2-4 \mathrm{~km}$ (Fig. 5a). The result is that too much latent heat is accumulated in the model from the lower to the upper troposphere (Fig. 5c), which leads to an increase in the column thickness and a tendency for decreasing surface pressures (Fig. 3b). By contrast, the $Q_{\mathrm{ELD}}$ profile has net heating in the upper troposphere that is partially offset by net cooling in the lower troposphere, which would lead to smaller surface pressure falls.

Sanabia (2010) documented that the reintensification of Typhoon Sinlaku occurred as a sequence of cloud clusters formed progressively closer to the center after the decay of the older convection in an outer rainband (Figs. 4c and 4d). Whereas WRF tends to predict this sequential evolution of convection closer to the center, COAMPS-TC predicted strong convective bursts outward from the center that were less efficient to reintensify the circulation in the Typhoon Sinlaku. COAMPS-TC SLP did not decrease $(990.9-991.0 \mathrm{hPa})$ in the $6 \mathrm{~h}$ following 0000 UTC (Fig. 3b). Thus, the critical factor in the differences in SLP evolution between COAMPS-TC and WRF is the locations of those heating maxima relative to the circulation center.

\section{c. Evolution of pre-Nuri TD (case 2)}

According to the JTWC, the pre-Nuri tropical disturbance was near $13.2^{\circ} \mathrm{N}, 146.8^{\circ} \mathrm{E}$ at 0000 UTC 16 August 2008 and moved westward to near $13.2^{\circ} \mathrm{N}, 145.2^{\circ} \mathrm{E}$ at 0600 UTC. Convective clusters to the north and south of the circulation center were observed by ELDORA between 0000 and 0200 UTC and between 0315 and 0345 UTC 16 August, respectively (Table 1). Park and
Elsberry (2013) argued that it was the southern convective burst [designated as the $\mathrm{E} 3$ region in Fig. $1 \mathrm{f}$ in Park and Elsberry (2013)] that had latent heating and cooling rate distributions favorable for tropical cyclone formation. Indeed, this southern convective burst can be traced to the location where the pre-Nuri tropical depression developed at 1800 UTC 16 August according to the JTWC.

The WRF simulation was initialized at 1200 UTC 15 August, which is about $12-15 \mathrm{~h}$ before the ELDORA observations, and was integrated until 1800 UTC 16 August (Table 2). After $19 \mathrm{~h}$ of integration, WRF (Fig. 6a) predicted a 850-hPa low (geopotential height $<$ $1495 \mathrm{~m}$ ) near $16^{\circ} \mathrm{N}, 146.5^{\circ} \mathrm{E}$, which was $2.8^{\circ}$ longitude north of the JTWC pre-Nuri location at 0600 UTC 16 August. This low-level circulation center was about $2^{\circ}$ north of the center of the $500-\mathrm{hPa}$ low that is near $14^{\circ} \mathrm{N}$ (Fig. 6c). Although convection had been slow to develop near the low-level center, at 0700 UTC 16 August WRF predicted organized convective clusters with reflectivities greater than $42 \mathrm{dBZ}$ near the center of low-level circulation and the widespread decline of convection to the south near the midlevel circulation center. The organized convective bursts in the box region designated in Fig. 6a are considered to correspond reasonably well with the southern convective burst observed by ELDORA.

\section{d. Equivalent latent heating and cooling rates for pre-Nuri simulation}

The primary focus in this subsection is whether similar biases in the radar-equivalent model latent heating and cooling rates occur for the pre-Nuri formation stage as in 

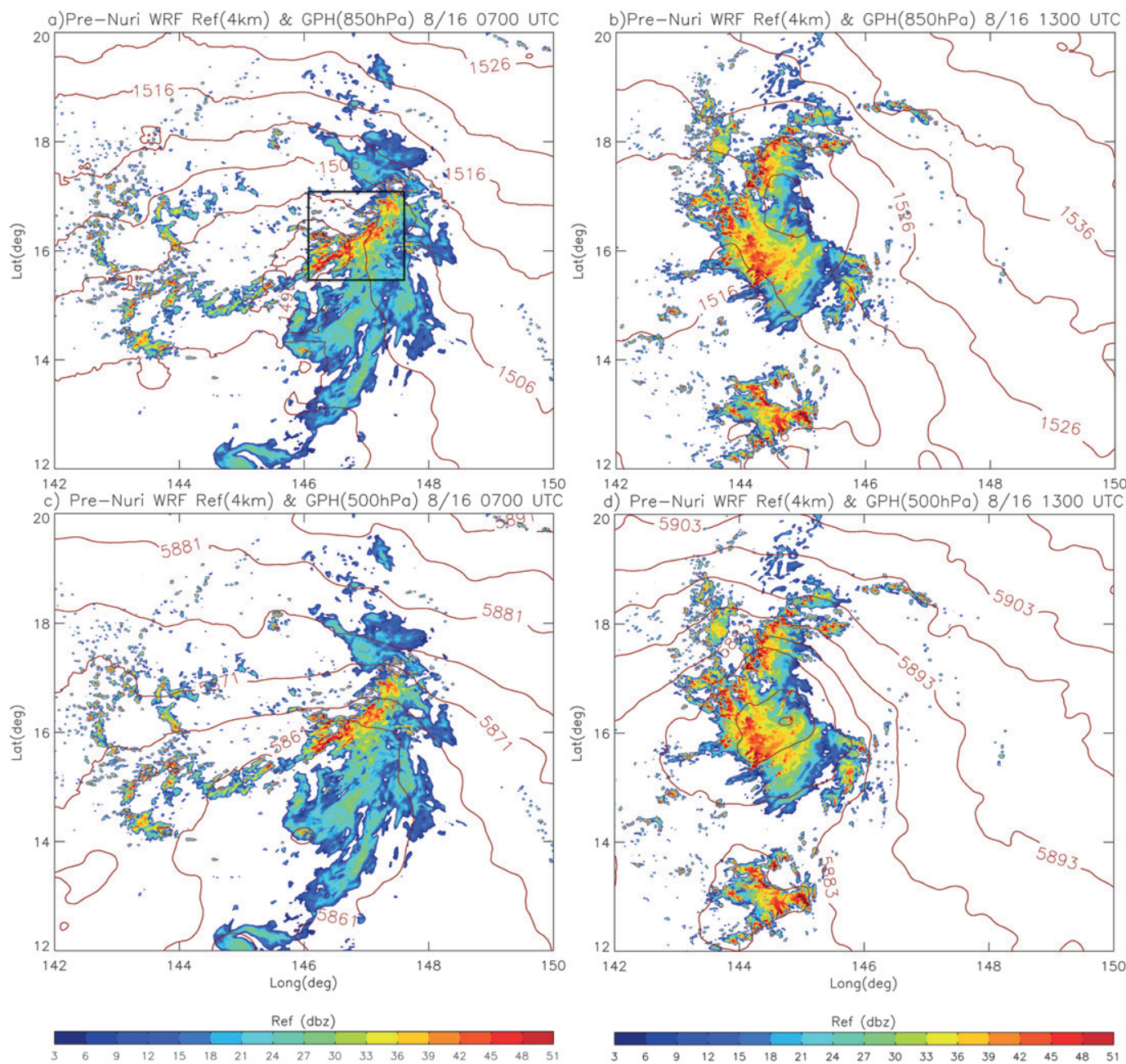

FIG. 6. Simulated reflectivities (dBZ; color scale at bottom) at $4 \mathrm{~km}$ for pre-Nuri and geopotential height at $850 \mathrm{hPa}$ (contours, m) by WRF at (a) 0700 and (b) 1300 UTC 16 Aug and the corresponding geopotential heights at $500 \mathrm{hPa}$ (contours, m) at (c) 0700 and (d) 1300 UTC. The box in (a) indicates the region in which the CFADs in Fig. $7 \mathrm{a}$ and the net latent heating profile (solid line) in Fig. $7 \mathrm{c}$ are calculated.

the pre-reintensification of Typhoon Sinlaku in section 3b. Notice the WRF heating rates (Fig. 7a) for less frequently occurring convective cells tend to be overestimated relative to the ELDORA rates (Fig. 7b) for this case. Furthermore, these overestimates for the WRF heating rates (Fig. 7a) are distributed over a deeper vertical layer between 2 and $9 \mathrm{~km}$ rather than being concentrated in the low to midtroposphere between 2 and $6 \mathrm{~km}$ as revealed by ELDORA observations (Fig. 7b).

As was the case for pre-reintensifying Typhoon Sinlaku, the WRF (Fig. 7a) simulation underestimated the cooling magnitudes relative to the ELDORA cooling rates (Fig. 7b) for the less frequently occurring cells. This deficiency of the WRF numerical simulation is again attributed to an improper representation of evaporative cooling rates where precipitation falls into drier air from the tilted, deep convective towers. In this pre-Nuri case, the vertical wind shear was smaller with less extreme tilting, and at the more tropical location of pre-Nuri, a more moist midtroposphere is expected to lead to less evaporative cooling.

The much larger heating rates than cooling rates for WRF leads to an area-averaged net heating that is somewhat larger than the ELDORA net heating through most of the layer (Fig. 7c). In particular, the WRF maximum at around $8 \mathrm{~km}$ is almost double the ELDORA value, and with another net heating peak around $3 \mathrm{~km}$. The effect of the double maxima of heating on the pressure field during the next $6 \mathrm{~h}$ is indicated in Fig. 6. A somewhat better organized 850 -hPa circulation was predicted by WRF at 1300 UTC (Fig. 6b) compared to the open wave at 0700 UTC (Fig. 6a). This tendency to spin 
a) CFADs of Qwrf (Case ॥ Pre-Nuri)

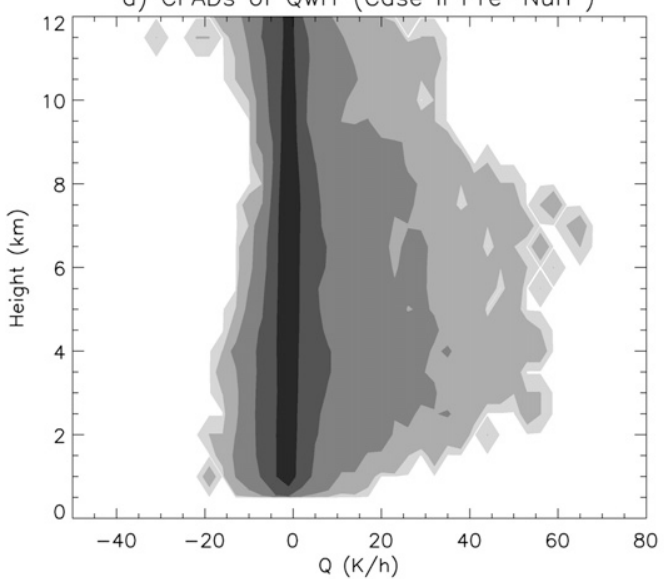

b) CFADs of Qeld (Case ॥ Pre-Nuri )

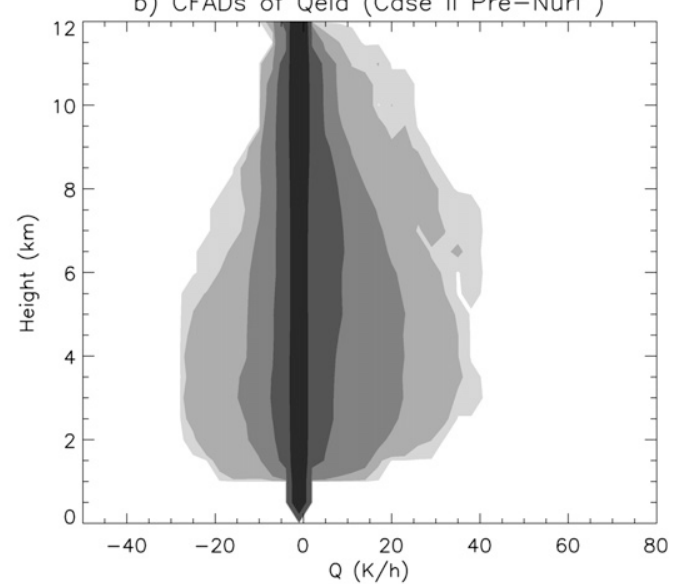

Exponent of normalized frequency

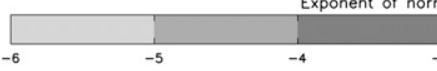

c) Net heating/cooling rate

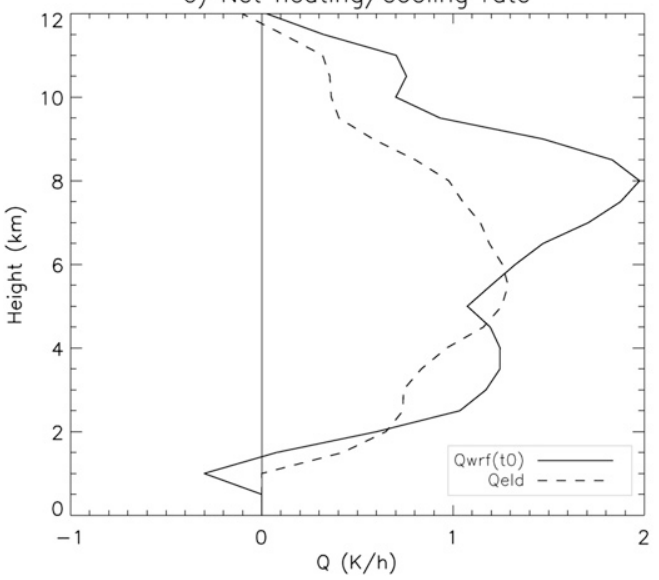

d) Change in WRF net DIV in next $6 \mathrm{~h}$

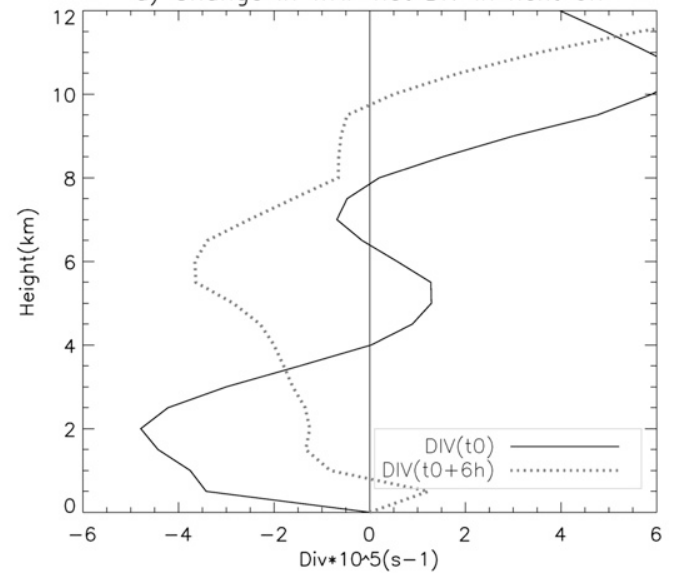

FIG. 7. (a)-(c) As in Fig. 5, but for the pre-Nuri case. (d) Vertical profiles of area-averaged divergence $\left(10^{-5} \mathrm{~s}^{-1}\right)$ at $0700 \mathrm{UTC}\left[\mathrm{DIV}\left(t_{0}\right)\right.$ with solid line] and $1300 \mathrm{UTC}\left[\mathrm{DIV}\left(t_{0}+6 \mathrm{~h}\right)\right.$ with dotted line] 16 Aug within $75 \mathrm{~km}$ of the 850-hPa low center. The divergence profile at 0700 UTC corresponds to the $Q_{\text {WRF }}$ heating profile in Fig. 6c.

up the low-level cyclonic circulation is consistent with a maximum of heating at $3 \mathrm{~km}$ and cooling at $1 \mathrm{~km}$, since this heating profile implies a vertical stretching of the layer with compensating convergence that would tend to spin up the vortex in that layer. However, a notable deepening was predicted at $500 \mathrm{hPa}$ (cf. Figs. 6d and $6 c$ ) that can be attributed to the larger net heating at $8 \mathrm{~km}$. Again, vertical stretching of the layer below the level of maximum of heating leads to compensating horizontal convergence, and indeed a maximum of convergence at $6 \mathrm{~km}\left(4 \times 10^{-5} \mathrm{~s}^{-1}\right)$ was predicted at 1300 UTC (Fig. 7d). By contrast, the net heating profile from the ELDORA observations with a maximum at $5 \mathrm{~km}$ (Fig. 7c) is expected to lead to a spinup of cyclonic vorticity below that layer.

In summary, excessive heating rates and smaller cooling rates relative to the ELDORA retrievals are predicted by WRF in the pre-Nuri case. The net heating in the area with a double maximum leads to an overestimate of the deepening in the midtroposphere and an underestimate of the deepening in the lower troposphere. This is an illustration that it is not just the maxima of the heating and cooling rates that are important; the model must also correctly predict the vertical profile of the net heating rate to accurately predict the intensification to a tropical cyclone.

\section{Simulations of nondeveloping systems}

It is also important that the numerical models be able to correctly predict the nondevelopment as well as the development of tropical disturbances. In this section, the WRF and the COAMPS-TC simulations for TCS25 will be discussed in sections $4 \mathrm{a}$ and $4 \mathrm{~b}$, and the WRF 
simulation for TCS51 will be discussed in sections $4 \mathrm{c}$ and $4 \mathrm{~d}$. The key question in these nondeveloping cases is thus whether the model-derived latent heating and cooling rates contain similar biases relative to the ELDORA retrievals as in the two developing cases.

\section{a. Simulations of TCS25 circulation (case 3)}

The TCS25 tropical disturbance was near $22.0^{\circ} \mathrm{N}$, $154.0^{\circ} \mathrm{E}$ at 0000 UTC 29 August based on the ECMWF analysis (Penny et al. 2010). The ECMWF minimum SLP of this circulation varies between 1004 and $1008 \mathrm{hPa}$ over the period of 28-30 August (Fig. 6 of Penny et al. 2010). Although the system did not develop, the convection seemed to be organized. An active convective region south of the 850-hPa circulation center was observed by ELDORA between 0300 and 0330 UTC. These nondeveloping cases were particularly sensitive to the initial conditions, and thus several initial times were tested to find convective conditions analogous to those of the ELDORA observations. So long as a similar convective organization is found, the CFADs are not so sensitive to the precise position of the box because of the large area $\left(2^{\circ} \times 2^{\circ}\right)$ over which they are calculated.

WRF was initialized at 1200 UTC 27 August, which is about $39 \mathrm{~h}$ before the ELDORA observations, and was integrated until 1200 UTC 30 August. At 0300 UTC 29 August (Fig. 8a), WRF had predicted elongated convective bands cyclonically curving around a surface circulation. A minimum SLP less than $1002 \mathrm{hPa}$ was predicted in conjunction with the circulation near $22.5^{\circ} \mathrm{N}, 155.4^{\circ} \mathrm{E}$ that was just adjacent to the southern rainband. The convective burst south of the circulation center labeled "W-TCS25" region in Fig. 8a is selected because it is in a similar position relative to the circulation center as the ELDORA E4 region (Fig. 7c of Park and Elsberry 2013).

COAMPS-TC was initialized at 0000 UTC 28 August, which was $27 \mathrm{~h}$ before the ELDORA observations, and integrated until 0600 UTC 29 August. At 0000 UTC 29 August (Fig. 8c), COAMPS-TC predicted a stronger surface circulation with minimum SLP less than $995 \mathrm{hPa}$. The circulation center in COAMPS-TC was embedded in the head of a comma-shaped cloudy area rather than in a cloud-free region as in the WRF simulation, and as in the Multifunctional Transport SatelliteIR (MTSAT-IR) brightness temperatures (Penny et al. 2010; Fig. 2). Notice that COAMPS-TC predicted strong convective cells (reflectivities $>42 \mathrm{dBZ}$ ) along an elongated rainband region that extended hundreds of kilometers to the east of the circulation center, and with more extensive convective regions to the northwest and north. This tendency for COAMPS-TC to predict more extensive cloudy areas compared to WRF was also noted in the pre-reintensification Typhoon Sinlaku and pre-Nuri cases in sections $3 \mathrm{a}$ and $3 \mathrm{c}$. The region of convection south of the circulation center in the COAMPSTC simulation labeled "C-TCS25" in Fig. 8c is selected for comparison with the ELDORA-observed convective bursts.

\section{b. Equivalent retrievals of model latent heating and cooling rates for case 3}

As in the pre-Nuri case 2, the WRF radar-equivalent heating rates (Fig. 9a) for the nondeveloping TCS25 case are significant overestimates relative to $Q_{\mathrm{ELD}}$ (Fig. 9c) for the less frequently occurring convective cells (normalized frequencies $<10^{-3}$ ). Whereas the WRF heating rate maxima are about 25,45 , and $60 \mathrm{~K} \mathrm{~h}^{-1}$ for the three infrequent contours (Fig. 9a), the ELDORA heating rate maxima do not exceed $25 \mathrm{~K} \mathrm{~h}^{-1}$ (Fig. 9c). Similarly, the COAMPS-TC heating maxima tend to be excessive for the same frequency contours (Fig. 9b).

A notable characteristic in this nondeveloping case was that the ELDORA-derived maximum heating rates were in the middle to upper levels (Fig. 9c) rather than being concentrated at low levels as in the developing pre-Nuri case (Fig. 7b). In addition to the larger magnitudes, the maximum heating rates extend from lower to upper levels both in WRF (Fig. 9a) and COAMPS-TC (Fig. 9b), although COAMPS-TC also has some large heating rates at very low levels. Such overestimated, deeper heating maxima may have been expected for the developing cases, such as pre-Nuri, rather than in this nondeveloping case.

As for the two developing cases, the less frequently occurring maximum cooling rates (Figs. 9a and 9b) were somewhat smaller than the ELDORA cooling rates (Fig. 9c). In particular, WRF did not have a cooling maximum at upper levels (around $7-8 \mathrm{~km}$ ) as in the ELDORA rates. Similarly, COAMPS-TC did not have an upper-level cooling maximum for the less frequently occurring cells (Fig. 9b).

In summary, the numerical simulations had larger heating rates than the ELDORA rates in the regions of less frequent but strong convection. By contrast, the cooling rates are smaller than the ELDORA rates. Accordingly, these biases for the nondeveloping TCS25 case are similar to the biases for the pre-Nuri developing case.

Except for the absence of a well-defined lowertropospheric maximum heating rate, the net heating rate profile for WRF for case 3 (Fig. 9d) has a similar vertical profile as for case 2 (Fig. 7c). By contrast, ELDORA has a small net heating at very low levels and slight cooling above $6 \mathrm{~km}$. In the WRF simulation (Fig. 8a), the rainbands are wrapping around the broad center, which suggests that compensating subsidence may be occurring 

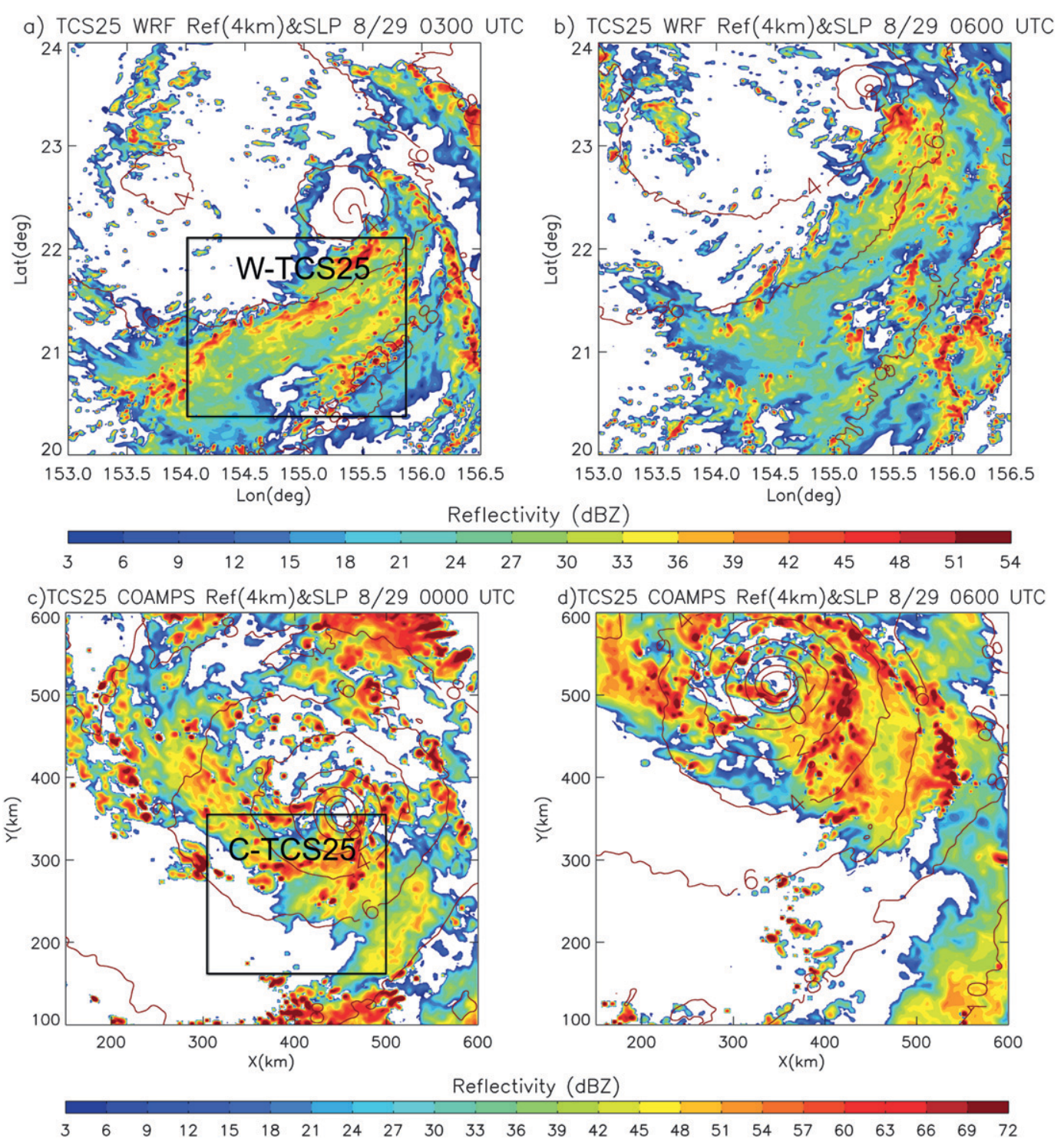

FIG. 8. Simulated reflectivities (shading, dBZ) at $4 \mathrm{~km}$ for TCS25 and SLP - $1000 \mathrm{hPa}$ (red contours, 2-hPa interval) by WRF at (a) 0300 and (b) 0600 UTC 29 Aug, and the COAMPS-TC simulated reflectivities (shading, $\mathrm{dBZ}$ ) and SLP - $1000 \mathrm{hPa}$ (red contours) at (c) 0000 and (d) 0600 UTC 29 Aug.

over the center that would contribute to further development. Indeed, the convective bands to the east of the center have become more organized by 0600 UTC 29 August (Fig. 8b) and a minimum SLP less than $1002 \mathrm{hPa}$ has been predicted. Whereas WRF has predicted a surface pressure fall greater than $4 \mathrm{hPa}$ between 0300 (Fig. 8a) and 0600 UTC (Fig. 8b), the ECMWF analyses indicate a pressure rise of about $4 \mathrm{hPa}$ between 0000 and 0600 UTC (Penny et al. 2010, their Fig. 6).

What aspect of the WRF heating rate profile with excessive latent heating rates over a deep tropospheric layer (Figs. 9a and 9d) likely contributed to the predicted a spinup of the circulation, when TCS 25 in fact did not develop? The profiles of heating and cooling rates were calculated separately for the grid points with normalized frequencies less than $10^{-3}$ and for frequencies greater than $10^{-3}$, which account for about $10 \%$ and about $90 \%$ of the grid points, respectively. Despite the smaller frequencies and smaller number of grid points, the larger heating and cooling rates contribute about $80 \%-100 \%$ of the net heating rates at low levels $(1-4 \mathrm{~km})$ over the $2.0^{\circ}$ box region for WRF. Thus, the lower-tropospheric heating of the less frequently occurring convection is considered to have the major contribution to the spinup of the vortex in WRF.

The COAMPS-TC model also predicted a surface pressure fall of about $4 \mathrm{hPa}$ between 0000 (Fig. 8c) and 

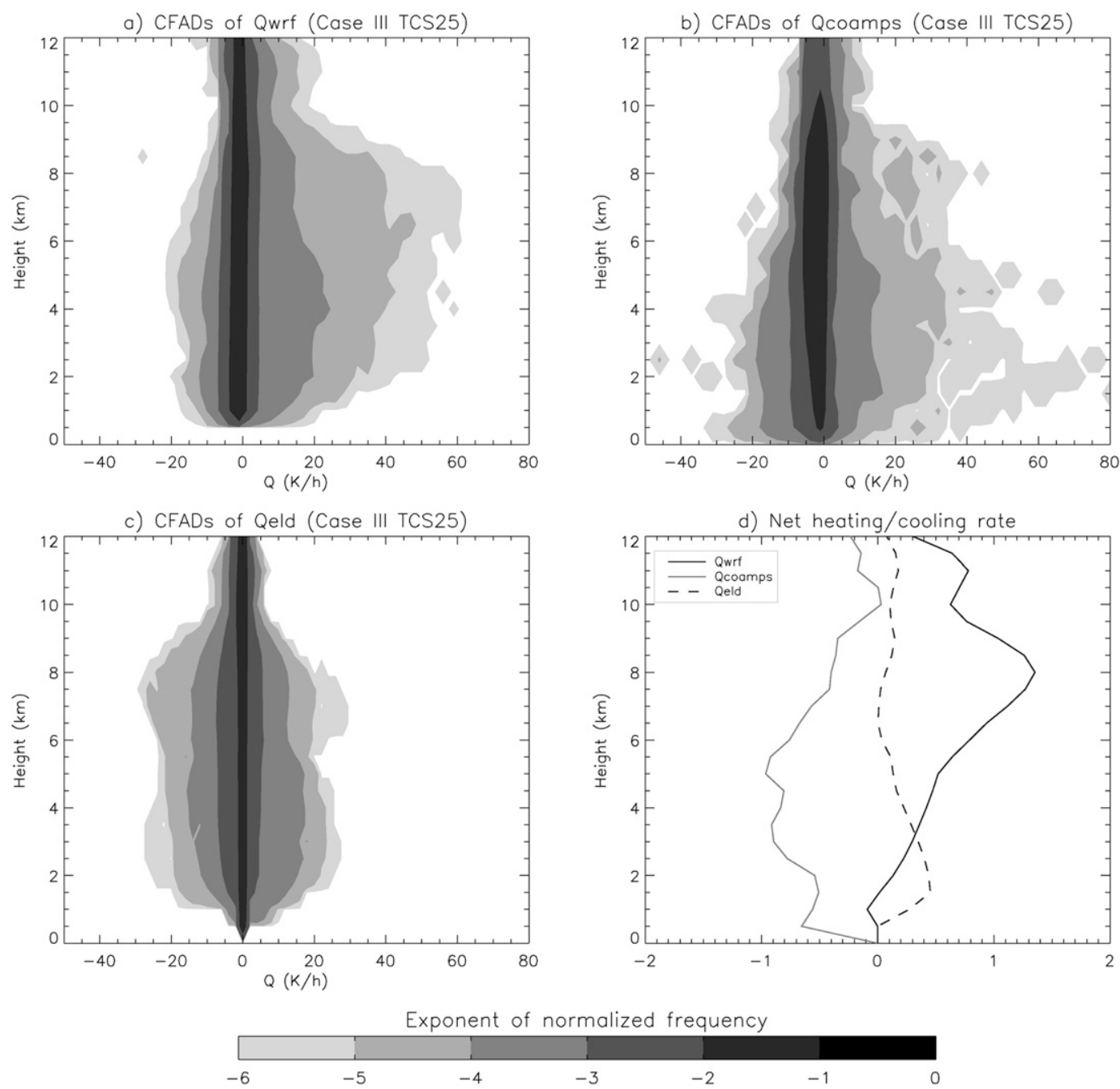

FIG. 9. (a),(c),(d) As in Figs. 5a-c, but for the TCS25 case, and (b) the corresponding COAMPS-TC rates and profile over the box domains in Fig. 8. The gray line in (d) is the COAMPS-TC net heating/cooling rates.

0600 UTC (Fig. 8d). Since convection was already predicted in all quadrants around the central region by 0000 UTC (Fig. 8c), and the maximum heating rates were in the lower troposphere (Fig. 9b), these were favorable conditions for continued deepening. However, the areaaveraged COAMPS-TC heating profile has negative values (Fig. 9d). This unexpected result may be attributed to the overestimated cooling rates for more frequently occurring cooling cells $\left(10^{-3}\right.$ contour in Fig. $\left.9 \mathrm{~b}\right)$ that may have been associated with a deep-convection-free region to the north of the center at 0000 UTC (Fig. 8c). Recall also that only radar-equivalent heating/cooling rates are being compared in Fig. 9, and that some of the large instantaneous heating rates in the models (e.g., Fig. 2a for the WRF simulation of TCS25) may be also contributing to the organization and net heating in the convection around the center.

\section{c. Simulations of nondeveloping TCS51 circulation (case 4)}

At 0000 UTC 4 October, the center of the TCS51 circulation was near $10.5^{\circ} \mathrm{N}, 132.5^{\circ} \mathrm{E}$ with a minimum sea level pressure less than $1008 \mathrm{hPa}$ according to the ECMWF analysis. At this time, the system was moving northward and weakening. Convective bursts south of the center were observed by the ELDORA during 02000230 UTC (Fig. 10a; Fig. 6f of Park and Elsberry 2013). This convection developed in a region of strong vertical wind shear (200-850-hPa shear magnitude $>10 \mathrm{~m} \mathrm{~s}^{-1}$ ).

WRF was initialized at 1200 UTC 2 October, which is about $38 \mathrm{~h}$ before the ELDORA observations, and was integrated until 0000 UTC 5 October. WRF predicted a minimum SLP of less than $1007.5 \mathrm{hPa}$ near $12.0^{\circ} \mathrm{N}$, $134.0^{\circ} \mathrm{E}$ at $0400 \mathrm{UTC} 4$ October (Fig. 10c), with a cluster 
a) YOTC SLP \& TRMM 3B42 rain OOOOUTC
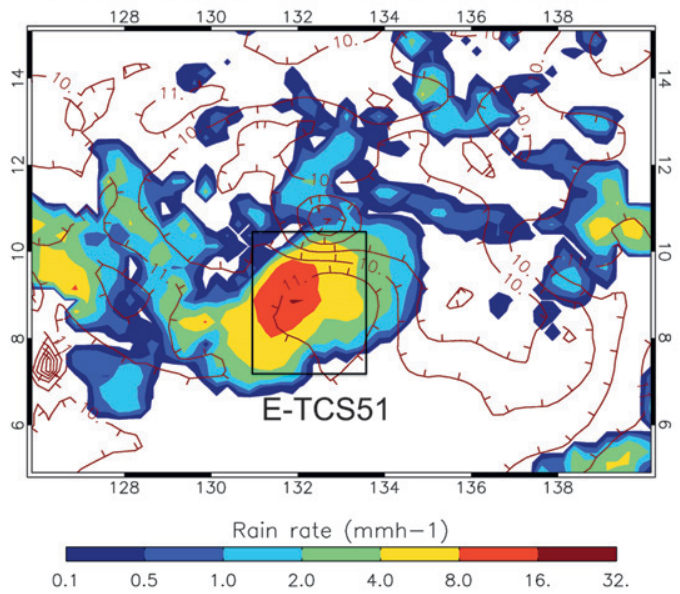

c) WRF SLP \& Reflectivity $4 \mathrm{~km} 0400$ UTC

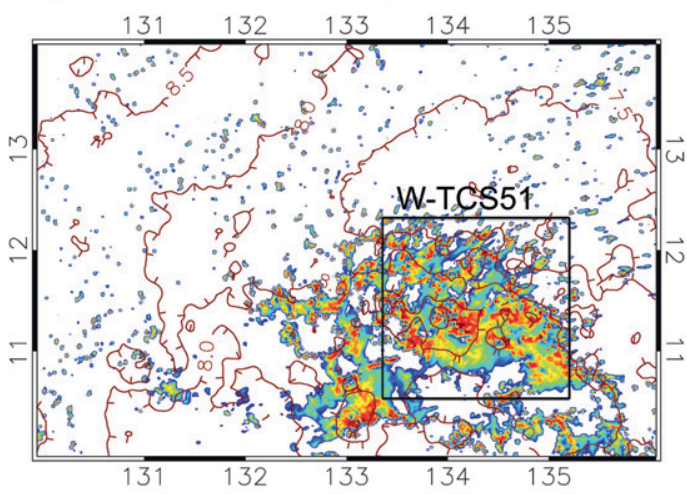

Reflectivity (dBZ)

$\begin{array}{llllllllllllllllll} & 6 & 9 & 12 & 15 & 18 & 21 & 24 & 27 & 30 & 33 & 36 & 39 & 42 & 45 & 48 & 51 & 54\end{array}$ b) YOTC SLP \& TRMM 3B42 rain 0600UTC

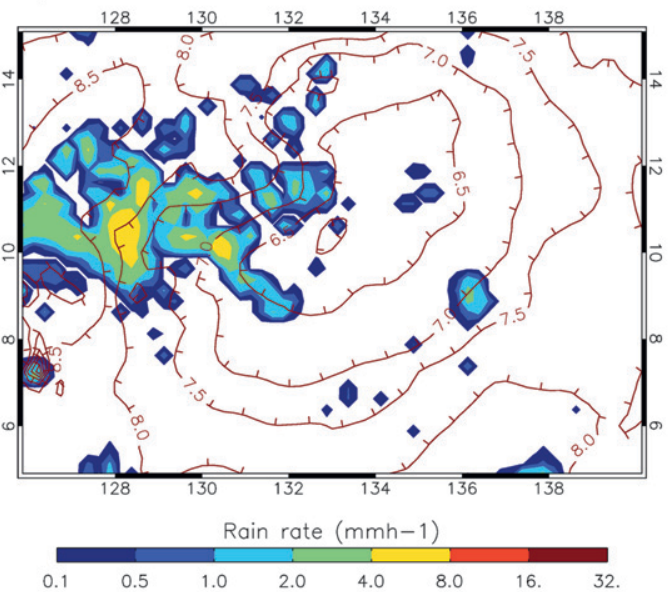

d) WRF SLP \& Reflectivity $4 \mathrm{~km} 1000$ UTC

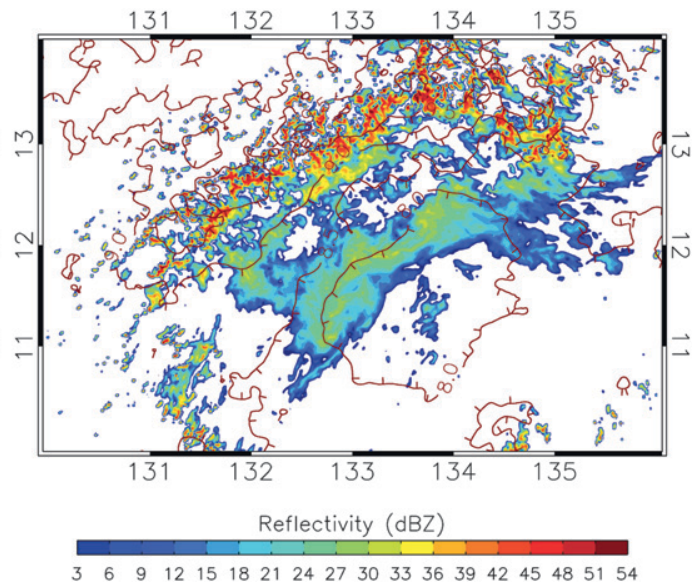

FIG. 10. SLPs (red contour, with 0.5 -hPa interval) for TCS51 from ECMWF analyses with surface rain rate (colors, $\mathrm{mm} \mathrm{h}^{-1}$ ) from TRMM 3B42 at (a) 0000 and (b) 0600 UTC 4 Oct, and WRF-simulated SLP (red contours) and reflectivities (colors, dBZ) at $4 \mathrm{~km}$ at (c) 0400 and (d) 1000 UTC 4 Oct. The box in (c) and (a) indicates the region over which the CFADs in Figs. 11a and 11b are calculated.

of strong convective cells with reflectivities greater than $36 \mathrm{dBZ}$ about $1^{\circ}$ south of the circulation center. The convective burst region labeled as W-TCS51 region in Fig. 10c corresponds well with the convective burst in the ELDORA-observed region (Fig. 10a).

\section{d. Equivalent retrievals of model latent heating and cooling rates for case 4}

As in the pre-Nuri and TCS25 case studies, the WRF simulation of the nondeveloping TCS51 has considerably overestimated heating rates for the less frequently occurring convective cells. Whereas the WRF heating rate maxima are about 40,70 , and $90 \mathrm{~K} \mathrm{~h}^{-1}$ for the frequency contours $10^{-4}, 10^{-5}$, and $10^{-6}$ (Fig. 11a), respectively, the ELDORA heating rate maxima are only 20,30 , and $40 \mathrm{~K} \mathrm{~h}^{-1}$ for the corresponding frequencies (Fig. 11b). For this case, the WRF underestimation of the heating rates relative to the ELDORA heating rates for the more frequently occurring cells (frequency contour of $10^{-3}$ ) cannot be attributed to ELDORA uncertainty. One difference for the TCS51 case from the pre-Nuri and TCS25 cases is that the WRF cooling rates are essentially the same as the ELDORA cooling rates for the same frequencies, rather than being smaller. With this exception, this simulation for the TCS51 case has similar biases as were found for the pre-Nuri and the TCS 25 cases. The magnitudes of cooling rates for the less frequently occurring cells were not large enough to offset the overestimated heating rates, which are estimated to contribute $71 \%$ of heating accumulation at upper levels. Accordingly, the magnitudes of the WRF net heating rate around $8 \mathrm{~km}$ were about 1.5 times larger than the magnitudes of net ELDORA heating (Fig. 11c). 
a) CFADs of Qwrf (Case IV TCS51)

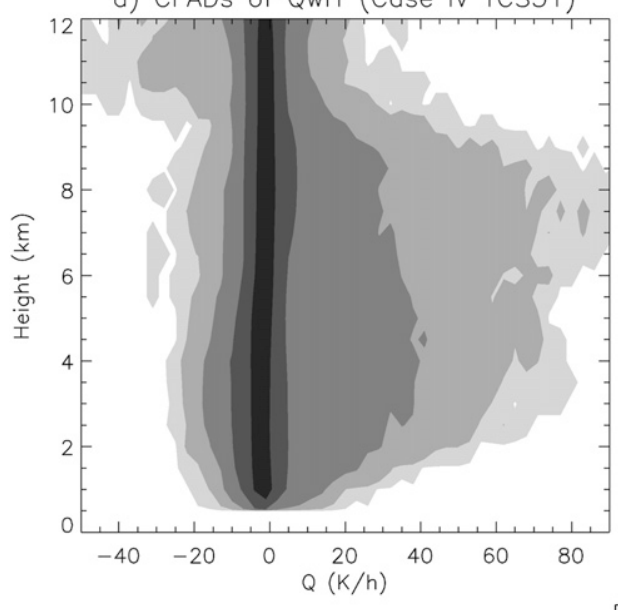

b) CFADs of Qeld (Case IV TCS51)

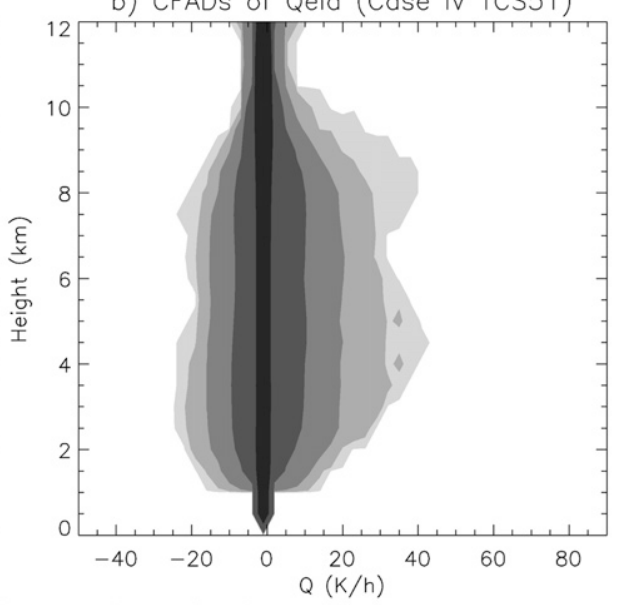

c) Net heating/cooling rate

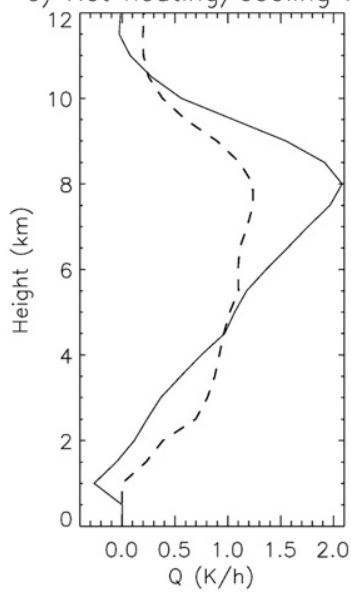

Exponent of normalized frequency

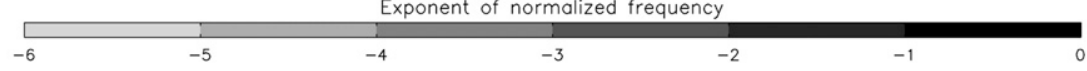

FIG. 11. As in Fig. 5, but for case 4 TCS51.

Although areas of active convection had been simulated at 0400 UTC 4 October, by 1000 UTC this convection had moved northward from the circulation center to the periphery of the region of SLP less than $1008 \mathrm{hPa}$ and had weakened significantly. The simulated weakening and northward movement are consistent with the TRMM 3B42 observations at 0600 UTC (Fig. 10b). Rather than a continuous heating source near the center of circulation, WRF has predicted a long and broad band of convective bursts much farther to the northwest. Although low SLPs are predicted along the convective band, the parent synoptic circulation is not deepened in this WRF simulation because the heating source was displaced from the circulation center (Nolan et al. 2007; Rogers 2010). In contrast, COAMPS-TC (with a 3-km grid) did simulate strong convective cells near the center of this synoptic-scale low (not shown) and the TCS51 circulation continued to deepen. This different COAMPS-TC result again highlights the importance of the location of the latent heating in addition to the magnitude and structure of the simulated latent heating rates.

\section{Summary and conclusions}

Latent heating and cooling rates have a critical role in predicting tropical cyclone formation and intensification (Nolan 2007; Braun et al. 2010). In Park and Elsberry (2013), the 3D, high-resolution latent heating and cooling rates were calculated from unique ELDORA observations during the TCS-08 field experiment in the western North Pacific. In this study, these ELDORA-derived latent heating and cooling rates are compared with the WRF and COAMPS-TC latent heating and cooling rates for two developing and two nondeveloping cases during TCS-08. As indicated in section 2, the instantaneous heating and cooling rates (e.g., LH in Fig. 2a) from the numerical simulations cannot be directly compared with the rates retrieved from the airborne radar observations that Park and Elsberry (2013) argue are representative of time scales of up to 5-10 min, which corresponds to the time for the forward- and backwardpointing antennas to view the area of convection. Accordingly, radar-equivalent heating rates are obtained by applying the radar thermodynamic retrieval algorithm [appendix A of Park and Elsberry (2013)] to the numerically simulated 3D wind and reflectivity values on a $1-\mathrm{km}$ grid. However, it is noted that the radar retrievals do not directly consider the snow and graupel contributions to the model heating rates.

The model integrations were initiated over a wide range of times in advance of the time of the ELDORA observations to obtain convective fields that resembled those in the four TCS-08 cases. As in Park and Elsberry (2013), the primary focus has been on the maximum heating and cooling rates for the normalized frequency contours $10^{-4}, 10^{-5}$, and $10^{-6}$ in the CFADs, since these frequencies have been shown to be associated with vigorously developing convective towers and the strong cooling rates in the nearby downdrafts (Rogers 2010). The more frequently occurring convective cells with smaller heating and cooling rates are considered to represent the "background" overturning convection that stabilizes the environment with net heating aloft and cooling below.

The primary conclusion of this study is that the radarequivalent model latent heating rates exceed the ELDORA heating rates and that the model cooling 
rates are smaller than the ELDORA cooling rates. The exceptions are the WRF simulation of the reintensification of Typhoon Sinlaku (section 3b) that had a distinctive upper-level heating maximum in the tilted deep convective towers, and that the maximum WRF cooling rates for the TCS51 case were essentially equivalent to the ELDORA cooling magnitudes. The reintensification of the Typhoon Sinlaku case predicted by WRF significantly underestimated the cooling associated with precipitation falling into the relatively dry atmosphere. In this case, the maximum model cooling rate was smaller and near the melting level rather than at lower levels.

In all four cases, the model cooling rates did not offset the corresponding heating rates and this resulted in a net heating in the columns primarily due to the less frequently occurring, but intense, convective cells. These positive heating biases and underestimated cooling magnitudes for less frequently occurring convective cells in the numerical models may be attributed to too-vertical deep convective cells and an underrepresentation of the saturated convective-scale downdrafts that generate the "cold pool." Overestimation of the heating in the low to upper levels is expected to generate larger lower-tropospheric convergence (Mapes and Houze 1995), which may produce stronger positive potential vorticity anomalies and overintensify the synoptic-scale circulations (Tory et al. 2006). Underrepresentation of the adjacent cool-pool region in the simulations may lead to weaker divergence. The most obvious effects of the excessive heating and underestimated cooling rates were in the WRF and COAMPS-TC simulations of the nondeveloping TCS25 (section 4b), so that a positive feedback occurred. The same biases were present in the TCS51 WRF simulation, but the strong convection was predicted to move far from the system center, which negated any tendency for overdeepening associated with excessive latent heating.

This is the first attempt in which the model-simulated velocities and reflectivities are utilized with a radarequivalent approach to calculate the 3D distribution of latent heating rates that may be directly compared with the ELDORA-derived heating and cooling rates. The primary conclusion regarding the least frequently occurring convective cells having larger heating rates and over a deeper layer than in the ELDORA retrievals suggests that the simulated intense convection has too large of a contribution to the vertical redistribution of heat in the models. In a few cases, such as TCS51, the smaller model heating rates relative to the ELDORA rates for the most frequently occurring convection suggests that the background overturning convection is having too small of a contribution to the vertical redistribution of heat.

This evaluation study of the radar-equivalent latent heating rates from numerical simulations is consistent with the Zhou et al. (2007) and Li et al. (2008) studies that found excessive model-simulated reflectivity values (e.g., $40 \mathrm{dBZ}$ ) in the middle and upper troposphere. As suggested by Lang et al. (2011), these biases could be due to excessive graupel and/or snow amounts, sizes, and densities. As in the application in this study, excessive model heating through a deep layer of the atmosphere may lead to overdeepening of the cyclonic circulation.

As in Park and Elsberry (2013), the comparisons of the model-derived latent heating and cooling rates with the ELDORA rates indicate an important contribution of the saturated convective-scale downdrafts in the formation of tropical cyclones. Although this study examines only a small dataset, the consistency of the results suggests a wider applicability. To enhance reliability of the tropical cyclone formation forecasts, an accurate prediction of the magnitudes of the evaporative cooling processes and of the cold pool is required. The underrepresentation of evaporative cooling in the numerical simulation may be partly due to uncertainties in the fall speeds of snow, graupel, and other precipitation particles (Yuter et al. 2006). Effects of precipitation falling into a drier atmosphere should be further examined via more direct observations of cloud microphysics and via numerical simulations with diverse parameterization schemes. Overall advances in the treatment of boundary layer processes, tropical convection, and microphysical processes are required to improve forecasts of tropical cyclone formation and intensification.

Acknowledgments. This study was performed during the first author's National Research Council (NRC) Research Associateship Program (RAP) at the Naval Postgraduate School (NPS), Monterey, California. The participation of the fourth author was also done during his NRC RAP at the Naval Research Laboratory. The participation of the second and third authors was funded by the Office of Naval Research (ONR) and the National Science Foundation. Computing resources at NPS were provided by the NPS High Performance Computing Center, and the initial conditions for the WRF integrations were provided by the European Centre for Medium-Range Weather Forecasts. The fourth and fifth authors acknowledge support through the ONR Program Element $0603207 \mathrm{~N}$ and support for computational resources through a grant from the Department of Defense (DoD) High Performance, with computing time from the DoD Supercomputing Resource Centers at Stennis Space Center in Mississippi and at Wright-Patterson Air force Base in Ohio. Mrs. Penny Jones provided skillful manuscript preparation assistance. 


\section{REFERENCES}

Braun, S. A., M. T. Montgomery, K. J. Mallen, and P. D. Reasor, 2010: Simulation and interpretation of the genesis of Tropical Storm Gert (2005) as part of the NASA Tropical Cloud Systems and Processes Experiment. J. Atmos. Sci., 67, 999-1025.

Chen, S., and Coauthors, 2003: COAMPS version 3 model description: General theory and equations. Naval Research Laboratory Tech. Rep. NRL/PU7500-04-448, 141 pp.

Dudhia, J., 1989: Numerical study of convection observed during the winter monsoon experiment using a mesoscale twodimensional model. J. Atmos. Sci., 46, 3077-3107.

1996: A multi-layer soil temperature model for MM5. Preprints, Sixth PSU/NCAR Mesoscale Model Users' Workshop, Boulder, CO, NCAR, 3 pp. [Available online at http://www. mmm.ucar.edu/mm5/lsm/soil.pdf.]

Elsberry, R. L., and P. A. Harr, 2008: Tropical Cyclone Structure (TCS08) field experiment: Science basis, observational platforms, and strategy. Asia-Pac. J. Atmos. Sci., 44, 209-231.

Fovell, R. G., K. L. Corbosiero, and H.-C. Kuo, 2009: Cloud microphysics impact on hurricane track as revealed in idealized experiments. J. Atmos. Sci., 66, 1764-1778.

Frank, N. L., 1970: Atlantic tropical systems of 1969. Mon. Wea. Rev., 98, 307-314.

Fritsch, J. M., and J. S. Kain, 1993: Convective parameterization for mesoscale models: The Fritsch-Chappell scheme. The Representation of Cumulus Convection in Numerical Models, Meteor. Monogr., No. 46, Amer. Meteor. Soc., 159-164.

Guimond, S. R., M. A. Bourassa, and P. D. Reasor, 2011: A latent heat retrieval and its effects on the intensity and structure change of Hurricane Guillermo (1997). Part I: The algorithm and observations. J. Atmos. Sci., 68, 1549-1567.

Harr, P. A., R. L. Elsberry, and J. C.-L. Chan, 1996: Transformation of a large monsoon depression to a tropical storm during TCM-93. Mon. Wea. Rev., 124, 2625-2643.

Harshvardhan, R. Davies, D. A. Randall, and T. G. Corsetti, 1987: A fast radiation parameterization for atmospheric circulation models. J. Geophys. Res., 92 (D1), 1009-1016.

Hendricks, E. A., M. T. Montgomery, and C. A. Davis, 2004: The role of "vortical" hot towers in the formation of Tropical Cyclone Diana (1984). J. Atmos. Sci., 61, 1209-1232.

Hildebrand, P. H., and Coauthors, 1996: The ELDORA/ASTRAIA airborne Doppler weather radar: High-resolution observations from TOGA COARE. Bull. Amer. Meteor. Soc., 77, 213-232.

Hodur, R. M., 1997: The Naval Research Laboratory's Coupled Ocean/Atmosphere Mesoscale Prediction System (COAMPS). Mon. Wea. Rev., 125, 1414-1430.

Hong, S.-Y., J. Dudhia, and S.-H. Chen, 2004: A revised approach to ice microphysical processes for the bulk parameterization of clouds and precipitation. Mon. Wea. Rev., 132, 103-120.

_- Y. Noh, and J. Dudhia, 2006: A new vertical diffusion package with an explicit treatment of entrainment processes. Mon. Wea. Rev., 134, 2318-2341.

Houze, R. A., Jr., 2004: Mesoscale convective systems. Rev. Geophys., 42, RG4003, doi:10.1029/2004RG000150.

Kain, J. S., 2004: The Kain-Fritsch convective parameterization: An update. J. Appl. Meteor., 43, 170-181.

Lander, M. A., 1994: Description of a monsoon gyre and its effect on the tropical cyclones in the western North Pacific during August 1991. Wea. Forecasting, 9, 640-654.

Lang, S. E., W.-K. Tao, X. Zeng, and Y. Li, 2011: Reducing the biases in simulated radar reflectivities from a bulk microphysics scheme: Tropical convective systems. J. Atmos. Sci., 68, 2306-2320.

Leise, J. A., 1982: A multi-dimensional scale-telescoped filter and data extension package. NOAA Tech. Memo. WPL-82, 19 pp.

Li, Y., E. J. Zipser, S. K. Krueger, and M. A. Zulauf, 2008: Cloudresolving modeling of deep convection during KWAJEX. Part I: Comparison to TRMM satellite and ground-based radar observations. Mon. Wea. Rev., 136, 2699-2712.

Mapes, B. E., and R. A. Houze, 1995: Diabatic divergence profiles in western Pacific mesoscale convective systems. J. Atmos. Sci., 52, 1807-1828.

Mlawer, E. J., S. J. Taubman, P. D. Brown, M. J. Iacono, and S. A. Clough, 1997: Radiative transfer for inhomogeneous atmospheres: RRTM, a validated correlated-k model for the longwave. J. Geophys. Res., 102 (D14), 16 663-16 682.

Montgomery, M. T., M. E. Nicholls, T. A. Cram, and A. B. Saunders, 2006: A vortical hot tower route to tropical cyclogenesis. J. Atmos. Sci., 63, 355-386.

Nolan, D. S., 2007: What is the trigger for tropical cyclogenesis? Aust. Meteor. Mag., 56, 241-266.

—, Y. Moon, and D. P. Stern, 2007: Tropical cyclone intensification from asymmetric convection: Energetics and efficiency. J. Atmos. Sci., 64, 3377-3405.

_ J. A. Zhang, and D. P. Stern, 2009: Evaluation of planetary boundary layer parameterizations in tropical cyclones by comparison of in situ observations and high-resolution simulations of Hurricane Isabel (2003). Part I: Initialization, maximum winds, and the outer-core boundary layer. Mon. Wea Rev., 137, 3651-3674.

Park, M.-S., and R. L. Elsberry, 2013: Latent heating and cooling rates in developing and nondeveloping tropical disturbances during TCS-08: TRMM PR vs ELDORA retrievals. J. Atmos. Sci., 70, 15-35.

Penny, A. B., S. V. Malvig, and P. A. Harr, 2010: The role of multiple mesoscale convective systems in a non-developing tropical disturbance observed during the Tropical Cyclone Structure-2008 (TCS-2008) field experiment. Preprints, 29th Conf. on Hurricanes and Tropical Meteorology, Tucson, AZ, Amer. Meteor. Soc., 11A.5. [Available online at https:// ams.confex.com/ams/29Hurricanes/techprogram/paper_169024. htm.]

Ritchie, E. A., and G. J. Holland, 1999: Large-scale patterns associated with tropical cyclogenesis in the western Pacific. Mon. Wea. Rev., 127, 2027-2043.

Rogers, R. F., 2010: Convective-scale structure and evolution during a high-resolution simulation of tropical cyclone rapid intensification. J. Atmos. Sci., 67, 44-70.

—, M. L. Black, S. S. Chen, and R. A. Black, 2007: An evaluation of microphysics fields from mesoscale model simulations of tropical cyclones. Part I: Comparisons with observations. J. Atmos. Sci., 64, 1811-1834.

Roux, F., V. Marécal, and D. Hauser, 1993: The 12/13 January 1988 narrow cold-frontal rainband observed during MFDP/ FRONTS 87. Part I: Kinematics and thermodynamics. J. Atmos. Sci., 50, 951-974.

Rutledge, S. A., and P. V. Hobbs, 1984: The mesoscale and microscale structure and organization of clouds and precipitation in midlatitude cyclones. XII: A diagnostic modeling study of precipitation development in narrow cold-frontal rainbands. J. Atmos. Sci., 41, 2949-2972.

Sadler, J. C., 1976: A role of the tropical upper tropospheric trough in early season typhoon development. Mon. Wea. Rev., 104, $1266-1278$. 
Sanabia, E., 2010: Re-intensification of Typhoon Sinlaku (2008). Ph.D. dissertation, Naval Postgraduate School, $233 \mathrm{pp}$.

Skamarock, W. C., and Coauthors, 2008: A description of the Advanced Research WRF version 3. NCAR Tech. Note NCAR/TN-475+STR, 123 pp.

Tiedtke, M., W. A. Heckley, and J. Slingo, 1988: Tropical forecasting at ECMWF: The influence of physical parameterization on the mean structure of forecasts and analyses. Quart. J. Roy. Meteor. Soc., 114, 639-664.

Tory, K. J., M. T. Montgomery, and N. E. Davidson, 2006: Prediction and diagnosis of tropical cyclone formation in an NWP system. Part I: The critical role of vortex enhancement in deep convection. J. Atmos. Sci., 63, 3077-3090.
Wang, S., Q. Wang, and J. S. Doyle, 2002: Some improvement of Louis surface flux parameterization. Preprints, 15th Symp. on Boundary Layers and Turbulence, Wageningen, Netherlands, Amer. Meteor. Soc., 13.3a. [Available online at https://ams.confex.com/ams/BLT/techprogram/paper_44519. htm.]

Yuter, S. E., D. E. Kingsmill, L. B. Nance, and M. Löffler-Mang, 2006: Observations of precipitation size and fall speed characteristics within coexisting rain and wet snow. J. Appl. Meteor. Climatol., 45, 1450-1464.

Zhou, Y. P., and Coauthors, 2007: Use of high-resolution satellite observations to evaluate cloud and precipitation statistics from cloud-resolving model simulations. Part I: South China Sea Monsoon Experiment. J. Atmos. Sci., 64, 4309-4329. 